\title{
TUTELA SUMARIA DE DERECHOS EN EL PROCESO CIVIL: MISIÓN Y VISIÓN EN LATINOAMÉRICA
}

SUMMARY GUARANTEE OF RIGHTS

IN THE CIVIL PROCESS:

MISSION AND VISION IN LATIN AMERICA

Álvaro Pérez Ragone*

\section{Resumen}

Con la voz 'sumario' en Latinoamérica se alude a diferentes modalidades para la gestión de la variable y riesgo de la duración del proceso. Si bien no hay una univocidad que refiere a una variable más para distribuir entre las partes la duración de un proceso. La posibilidad de acceder a lo sumario en cualesquiera de sus modalidades ya mencionadas no solo se funda en casos de (i) "urgencia" y necesidad de una respuesta jurisdiccional rápida (ii) sino que, también, el criterio de un derecho evidente alegado por el demandante y en un tipo de controversia que se asume como de mayor simplicidad o una conducta determinada del demandado justifican también distribuir el riesgo en favor del que requiere la aplicación de ese tipo de procedimiento.

Palabras clave: Tutela sumaria, proceso civil, simplificación

\section{AbStRact}

With the word "summary" it is means different modalities for the proceeding's delay and time risk management. The word "summary" has not a uniform meaning in Latin America. It is one more variable to distribute

* Profesor Derecho Procesal Civil, Universidad Católica del Norte (Antofagasta). Dirección postal: Angamos N 0610, Antofagasta. Correo electrónico: alvaro.perez01@ ucn.cl. Artículo recibido el 12 de noviembre de 2016 y aceptado para su publicación el 11 de abril de 2017.

Relatoría general presentada en las XXV Jornadas Iberoamericanas de Derecho Procesal (Recife 2016) (Esta ponencia es parte del proyecto FONDECYT regular N¹150468 "Dirección material y gestión eficiente de los procesos civiles"). 
between claimant and defendant the duration of a process. The possibility of access to the summary in any of its aforementioned modalities is not only based on cases of: (i) "urgency" and the need for a accelerated judicial decision; (ii) also the criterion of an obvious or more probable right alleged by the plaintiff or a specific conduct of the defendant could justify a simplification of rituality or standard of proof. Insofar it is justified distributing the time risk management in favor of one party.

Key words: Summary relief, civil procedure, simplification.

\section{INTRODUCCIÓN}

La finalidad del proceso civil no puede ser reducida solo a la solución de controversias. La jurisdicción mediante el proceso persigue prioritariamente la oportuna y adecuada tutela de los derechos cuya protección es requerida. De esta forma, no solamente se tutelan los derechos resolviéndose las controversias sino, además, se hacen efectivos los beneficios para la sociedad en su conjunto ${ }^{1}$. La necesidad de prestar atención al derecho sustantivo a ser tutelado impone adecuar procesos y procedimientos que consideren alguno de los dos motivos generales que justifican la "sumariedad". Parece ser una preocupación a lo largo de la historia el justificar lo sumario como una entre tantas alternativas para dar respuesta a la demora en la protección de los derechos ${ }^{3}$. El problema de la lentitud irrazonable de la justicia civil no puede responderse únicamente con la implementación de procedimientos con mayor rapidez, celeridad o simplificación. La solución es mucho más compleja y multidisciplinaria ${ }^{4}$.

${ }^{1}$ Uzelac (2014), pp. 5-12; en el mismo sentido Diakonis (2014), pp. 18-27; Comp. Osti (2016), pp. 5-12.

${ }^{2}$ El término 'sumariedad' no existe en el Diccionario de la lengua española, por ello se lo cita entre paréntesis como descriptivo de todos los casos donde se da el fenómeno, de por sí plurívoco y multifuncional. Ya Víctor Fairen Guillen distinguía entre lo sumario en sentido formal en tanto supresión de actos y formalidades que reducían los tiempos de duración, y material en tanto limitación a la cognición del juez a determinadas cuestiones o prueba para poder decidir (1953) p. 384; Comp. estos criterios empleados con los propuestos por CARRATA (2012b), pp. 25-29; ANDREws (2009), pp. 47-55; Kofmel EHRENZELLER (2005), pp. 270-288.

${ }^{3}$ Montesano (1999), p. 309; Van Rhee (2004), pp. 1-21; cfr. Basilico (2010), pp. 737740; LOMBARDi (2010), pp. 473-494.

${ }^{4}$ Puede verse un diagnóstico y tratamiento de aspectos varios en relación con la necesidad de acelerar la justicia civil ya en la comunicación general en el primer Congreso Internacional de Derecho Procesal Civil el aporte de JАСов (1978), pp. 305-341; Comp. CARPI (1985), p. 456. 
Así, este artículo trata una dimensión (la procesal y procedimental) por lo que es acotada y parte por reconocer la necesidad de examen de otros elementos que no serán acá desarrollados. Con la voz 'sumario' se alude a diferentes modalidades para la gestión del riesgo tiempo en el proceso ${ }^{5}$. Es una variable más para distribuir entre las partes la duración de un proceso. La posibilidad de acceder a lo sumario en cualesquiera de sus modalidades ya mencionadas no solo se funda en casos de (i) "urgencia" y necesidad de una respuesta jurisdiccional rápida, (ii) sino que, también, el criterio de un derecho evidente alegado por el demandante y en un tipo de controversia que se asume como de mayor simplicidad o una conducta determinada del demandado justifican también distribuir el riesgo en favor del que requiere la aplicación de ese tipo de procedimiento. Es por ello que puede referirse a la decisión "sumaria" o a un procedimiento "sumario"6.

Un modelo procesal debe ser permeable a adecuar sus distintos procedimientos a particularidades del Derecho que en él se discute. Ello se relaciona con sistemas de flexibilización, sea externa mediante multipuertas adecuadas a la controversia, en algunos casos con una consiguiente especialización orgánica o "tribunales especializados"; o bien mediante una flexibilidad interna con un proceso único en el que las partes, o el tribunal puedan realizar adecuaciones para una mayor simplificación del proceso $^{8}$. Es un desafío intrínseco a los sistemas de justicia poder encontrar un equilibrio entre la rapidez (oportunidad) de la tutela y la seguridad jurídica de una decisión justa ${ }^{9}$. La impronta de la duración razonable del proceso no es, a su vez, una vía para justificar una rapidez sin mayor justificación y adecuados equilibrios ${ }^{10}$. Se puede, así, sostener como hipótesis que lo sumario se relacionaría con la adecuación procedimental a un derecho sustantivo que está urgido o, bien, tiene un estándar probatorio menos exigente compensado con una decisión provisoria que brinda cierta

${ }^{5}$ Para el examen del tiempo como riesgo y los problemas de previsibilidad véase Amrani-Mekri, Soraya (2010), pp. 249-268.

${ }^{6}$ Carrata (2012a), p. 1. Ya lo sostenía Adrian Zuckerman el uso (o peso) del tiempo en el proceso civil ha significado un permanente desafío para toda reforma de modo que pueda llegarse a una decisión oportuna y no tardía en la tutela de los derechos, ZuCKERMAN (1994), pp. 353-355.

${ }^{7}$ Comp. Kornhauser (2012), pp. 328-330; OECD (2013), “Giustizia civile: come promuoverne l'efficienza?", OECD Economics Department Policy Notes, No 18, p. 7. Implica en muchos casos reestructurar la competencia de los tribunales inferiores y el diseño orgánico para poder dar cabida a los jueces que entenderán en estas materias o supuestos de cuantía con procedimientos simplificados.

${ }^{8}$ Comp. Caponi (2016), pp. 823-832; Carrata (2012b). pp. 2-7.

${ }^{9}$ Settem (2016), pp. 114-118.

${ }^{10}$ Sobre los excesos en los argumentos y aplicación de la "duración razoble" véase VERDE (2011), p. 513. 
flexibilidad. La inclusión de lo sumario en cualquiera de sus acepciones siempre generó y genera temores frente al riesgo de una decisión injusta para el demandado por el tiempo y posibilidades para el ejercicio efectivo de su derecho de defensa ${ }^{11}$.

Para la formulación de este artículo se trabajó sobre la base de comunicaciones nacionales solicitadas a académicos de doce países latinoamericanos respecto de preguntas sobre el uso del término 'sumario' en sus modelos procesales, concentrándose la indagación en el proceso civil, excepcionalmente se hace referencia a la justicia de familia, constitucional o penal solo para comparar y fortalecer las conclusiones y observaciones en la justicia civil. Los resultados se analizan y entrelazan en cinco partes y una conclusión. En la sección II se aportan las visiones históricas y conceptuales sobre la protección sumaria de los derechos. En la siguiente parte (III) se exponen algunas acepciones y usos del término 'sumario'. Se prosigue con el examen de la técnica sumaria y los procedimientos simplificados en materia civil en litigios individuales como en colectivos (en sentido amplio en los que se incluirán mecanismos de acciones y tutela de derechos fundamentales también) (IV). Luego, se expone la aplicación del tema en lo cautelar y anticipatorio (v). Se cierra (VI) con una conclusión que hace un resumen de los puntos centrales desarrollados.

\section{LA PROTECCIÓN SUMARIA DE LOS DERECHOS}

En la teoría y en la práctica del proceso civil del Derecho Común entre los siglos XVIII y XIX, se distinguía entre los ordinarios y extraordinarios. Como especie de estos últimos, se mencionan los procesos sumarios, que, a su vez, se subdividían en indeterminados o regulares, y en determinados o irregulares. Los primeros se caracterizaban por ser más breves, rápidos, con una marcada reducción del tiempo para el conocimiento y la decisión. Los segundos, en cambio, además de tener las mismas características, también reducían o postergaban el ejercicio del derecho de defensa del demandado. A ello, hay que sumar la frecuencia en determinados casos para que, la mera posibilidad de ejercer una acción a través de dichos procedimientos era ya un antecedente suficiente para el convencimiento y la posterior decisión del tribunal ${ }^{12}$.

Bajo el nombre de "procedimientos sumarios", terminaron finalmente incluyéndose todos aquellos casos que no eran calificables de ordinarios, arribándose casi a una sinonimia entre procedimientos extraordinarios y

${ }^{11}$ Tronson (2016), pp. 183-202; Comp. Lombardi (2010), pp. 473-494.

${ }^{12}$ Briegleb (1859), pp. 83-84. 
sumarios. La característica determinante del proceso sumario, de acuerdo con el Derecho Común, fue la reducción de la causae cognitio a la summa causa $^{13}$. Aun cuando hubieren existido casos en los que su designación incluía la voz 'sumario', ello no solo podía referir a celeridad y la rapidez del proceso sino, también, a un conocimiento limitado y de simple verosimilitud, incluso, casos que para ser decididos era suficiente lo alegado y limitadamente acreditado por el demandante. Así, la simplificación del procedimiento relacionada con la intensidad y profundidad con la cual conocía el tribunal y decidía el tribunal ${ }^{14}$. Lo sumario fue históricamente visto en lo funcional (o simplificación de la cognición y prueba necesaria para motivar una decisión) o, bien, en lo estructural (simplificación del procedimiento $)^{15}$. Estos dos órdenes de análisis siguen vigente, pero con un agregado importante: la justificación constitucional y desde las garantías y derechos fundamentales constitucionales de disponer herramientas para una aceleración razonable del proceso en el otorgamiento de tutela del Derecho ${ }^{16}$.

\section{Misión de la tutela sumaria}

Tanto la diversificación como la unificación de los procedimientos generan desafíos para la adecuada y oportuna tutela de los derechos. La existencia de un tipo único de procedimiento tiene su contrapartida en la existencia de una multiplicidad de procedimientos, ambas alternativas parecen ser extremas. Un punto intermedio podría estar dado por la posibilidad de la gestión y del tipo único de procedimiento para permitir a vía sumaria ${ }^{17}$. Ello como reacción directa contra el mito del procedimiento ordinario (declarativo o de conocimiento) tradicionalmente rígido y justificado en los argumentos de un tratamiento igualitario y de una previsión normativa general de legalidad ${ }^{18}$. La cual no puede ser vista solo formalmente, sino que necesita de sustancialidad y ello se relaciona con la adecuación de las técnicas procesales a la tutela del Derecho según razones de justicia ${ }^{19}$.

${ }^{13}$ BAYer (1853), p. 2 y s.

${ }^{14}$ Biondi (1921), pp. 220-225.

${ }^{15}$ Válida también es esta distinción en la propuesta de CARRATA (2012a), p. 25 y s. al enunciar que puede haber un proceso sumario por ser simplificado o, bien, por el grado de cognición exigido.

${ }^{16}$ Ya sosteniendo esta perspectiva Јасов (1978), pp. 322-325; CARRATA (2012a), p. 24; Comp. Andrews (2009), pp. 47-55.

${ }^{17}$ Ya se describía ello como una "copiosísima flora procesal” Fairen Guillen (1953), p. 384. Comp. Basilico (2010), pp. 740-743.

${ }^{18}$ Cadiet (2008), pp. 133-150; Comp. Caponi (2016), pp. 823-832; Lombardi (2010), pp. 473-478; Carrata (2012a), pp. 5-12

${ }^{19}$ Comoglio (2008), p. 1513 y ss. 


\section{Del modelo de proceso único al diversificado}

El problema de la especialización de los procesos (o de los procedimientos) constituye un importante desafío para el proceso civil contemporáneo. El hecho de que exista una pluralidad de procesos especiales, la diversificación del rito es contrastable con el esquema de un modelo único aplicable a todo tipo de controversias, como ya se señaló. Los dos extremos están marcados por la superación o, al menos, por la necesidad de superar el dogma del modelo único de proceso civil que resulta difícilmente idóneo para la gestión, el conocimiento y la ulterior decisión de todo tipo de controversias $^{20}$. La unicidad de "procedimiento" tuvo un importante desarrollo a fines del siglo XIX y se consolidó durante el siglo Xx en la mayoría de los ordenamientos procesales, en especial en Latinoamérica, encontrándose actualmente en vía de cuestionamiento y en necesidad de superación. La pregunta es: ¿ cómo hacerlo? A fines del siglo Xx e iniciado el siglo XXI es posible referirse a dos vías:

i) La necesidad de la especialización se refiere no solo al tipo de procedimiento sino, también, al tribunal (esto implica una división entre la tarea jurisdiccional y el proceso por el cual se encausa) ${ }^{21}$. Así, se superaría la dificultad en la que se encuentra un juez que conoce de múltiples materias con diferentes tipos de procedimientos.

ii) A ello se suma la propuesta de flexibilizar los procedimientos para simplificarlos u ofrecer una opción menos compleja. Podría la sumarización ser el resultado de aquello.

Por su parte, la especialización del procedimiento se caracteriza como un supuesto de diversificación y de adecuación del modelo procesal a las circunstancias particulares de la controversia o litigio, lo que justifica salirse del estándar común o general ${ }^{22}$. A partir de ello surge y se consolida el fenómeno de la propuesta de mutación del rito del proceso declarativo o de conocimiento ordinario rígido y abstracto del Derecho cuya tutela se está solicitando.

La transformación del modelo único de proceso ordinario para adaptarlo a los distintos tipos de controversias tiene una especial relación con el principio de proporcionalidad en la distribución de los escasos recursos de la administración de justicia ${ }^{23}$. Determinados tipos de contiendas en razón de su naturaleza requieren de un menor tiempo y de-

${ }^{20}$ Es un desafío constante encontrar el equilibrio entre extremos planteados en término de garatismo o eficientismo, VAn RheE (2014), p. 61 y ss.; comp. Dondi, Ansanelli, CoMOGLIO (2015), pp. 342-344.

${ }^{21}$ Los términos 'juez' y 'tribunal' se usan en este texto indistintamente.

${ }^{22}$ CARPi (2003), p. 1009.

${ }^{23}$ Comp. Da Rós Bodart (2015), pp. 67-73; Voigt, Bialy (2013). 
dicación que otras. Ahora bien, el problema surge con los criterios de selección: ¿̇bajo qué condiciones se asignarán más o menos recursos para el conocimiento y decisión de los diferentes litigios? Ello conduce de manra inevitable a criterios de selección drásticos y en muchos casos podrían ser arbitrarios ${ }^{24}$. Los criterios suelen combinar la cuantía o el valor de aquello que es objeto del litigio con el tipo especial de materia.

i) Ciertos asuntos (independientemente sobre qué versen) se consideran complejos, ya sea por su elevada cuantía o, bien, por tratarse de determinadas materias, ellos se someten, así, a un proceso más complejo.

ii) En otros casos, su complejidad es menor, ya sea porque su cuantía es inferior o por su simpleza ${ }^{25}$. Son simples, ya que no revisten dificultades de hecho o de derecho:

(a) bien cuando no existe oposición de la contraparte (es decir, es una materia no controvertida) o

(b) habiendo oposición no revisten dificultad fáctica o jurídica. Sí se requiere ser cauto en determinar la materia para evitar el efecto regresivo y el uso abusivo o injusto del sistema ${ }^{26}$. Los litigios de menor complejidad revisten importancia. Primero, ya que a veces no son absorbidos por el sistema de justicia tradicional por el costo que significa para el Estado. Segundo, al quedar así "fuera del sistema" y latentes pueden agravarse y sumarse otros en el futuro. Finalmente, en el peor de los casos el justiciable ve sino resignado su derecho ${ }^{27}$. Contar con diversas alternativas para el ciudadano parece ser un mecanismo válido sumado a muchas otras condiciones para garantizar un adecuado acceso y un tránsito con un mayor nivel de justicia sustancial y procedimental ${ }^{28}$.

En algunos modelos procesales en Iberoamérica el fenómeno de la diversificación del rito ha ido de la mano de la especialización de los tribunales de justicia ${ }^{29}$. En este caso, se combina la creación de los tribu-

${ }^{24}$ Dondi, Ansanelui, Comoglio (2015), p. 343.

${ }^{25}$ Sobre las dificultades para conceptualizar lo "complejo" puede verse DondI (2011), pp. 3-17. La "complejidad" en este informe no refiere a complex litigation términos relacionados con class action, pero no solo a ello circunscripto con cierta dificultad para definirla BuRBANK (2011), pp. 43-61.

${ }^{26}$ Véase al respecto las conclusiones de la European Comission Directorate General Justice (2013), pp. 1-17, 44-71.

${ }^{27}$ CAppelletti, Garth (1978), p. 184.

${ }^{28}$ Véanse estos criterios en MA KO (2014), p. 3 y ss.

${ }^{29}$ La especialización como factor de eficiencia de la justicia puede verse en CARPI (2003), p. 1009 y ss.; Confr. la crítica contra especialización judicial en Doménech PASCUAL, Mora-SAnguinetTi (2015), pp. 2-33. 
nales especializados para conocer de determinadas materias con la especialización y las particularidades del procedimiento: así, por ejemplo, en el proceso laboral, en las causas que son de conocimiento de los tribunales de familia o de los tribunales comerciales. La especialización de los tribunales de justicia permite la diversificación, así como la adecuación del modelo procedimental a las condiciones y a las circunstancias propias de la controversia, sumado a lo que el juez debe decidir, conociendo solo ese tipo de materias. En este caso, la existencia de un tipo procesal único y de un juez especializado otorga un equilibrio aceptable ${ }^{30}$. Esto no excluye la posibilidad de que existan modelos o ritos procedimentales comunes o únicos adecuados y con un mayor o menor grado de flexibilización en las distintas materias de especialización judicial. Así, se combina una previsión general (de tramitación común), la cual será aplicada por un juez especializado en la materia, con una regulación tendencialmente única, pero adaptable a las condiciones y a las circunstancias que imponga el caso concreto ${ }^{31}$.

\section{Flexibilidad, simplificación y "sumariedad" procesal}

Los modelos informados se adecuan a las distintas alternativas existentes descritas del uso de lo sumario. Una primera opción contiene un proceso general, común u ordinario y uno o más caminos que son apenas una variante de aquel con la consiguiente enunciación de los casos especiales a los que este se aplica. Una segunda opción es la diversificación interna de un proceso único para adecuar su tramitación al momento de la configuración y la conformación de la controversia al ser conocida y decidida. Dentro de esta alternativa se puede dar una menor o una mayor cabida a la voluntad de las partes o al papel conductor del juez. Ello permitiría planificar y así maximizar el tiempo en coherencia con las características particulares de la controversia que deba conocerse y decidirse ${ }^{32}$.

Por una parte, se alude el argumento del "principio de legalidad" para imponer un único tipo de proceso y procedimiento, que sería respetuoso de las garantías del debido proceso, resguardando la legítima confianza

${ }^{30}$ Comp. Langbroek, Fabri (2007a), pp. 10-25; igualmente Langbroek, Fabri (2007b), p. 292 y ss.

${ }^{31}$ Ya sostenía Giuseppe Chiovenda la directa relación entre la confianza del ciudadano en el orden jurídico con la simplicidad de las formas Chiovenda (1923), p. 664; Comp. SETTEM (2016), pp. 74-73; un panorama general sobre la simplificación procesal véase Carrata (2015), pp. 1-14.

${ }^{32}$ La importancia en la planificación en cada caso redunda en beneficio tanto de las partes como del tribunal que pueden organizar su tiempo actual y futuro, ver lo sostenido sobre ello y la importancia para la eficiencia de la justicia civil en GALIC (2013), p. 72. 
y previsibilidad en todos los ciudadanos. Otra opción es sustentar la necesidad de una cierta flexibilidad, justamente para la efectividad de la tutela judicial de acuerdo con el derecho que debe protegerse ${ }^{33}$. Quizá sea necesario eludir el falso dilema entre la eficacia y eficiencia "o" la seguridad. Ambos integran un derecho fundamental procesal, que es el justo y racional proceso, por un lado. Por el otro, hay otros componentes que se suman a ellos, los que exceden el planteamiento del dilema inicial: el acceso, la eficacia, la eficiencia, la seguridad y otros deben ser observados. El criterio y el examen de proporcionalidad imponen una nueva visión entre la tutela judicial requerida y la técnica procesal para alcanzarla ${ }^{34}$. No hay una única forma de impartir justicia con seguridad, eficacia y eficiencia, a partir del Derecho Sustantivo que impone la adecuación de los medios para su tutela ${ }^{35}$. La flexibilidad del proceso parece ser importante, aunque desde las garantías del debido y justo proceso a veces es vista como inconveniente $^{36}$. Ahora bien, esas mismas garantías constitucionales, que a primera vista impondrían una cierta rigidez al proceso, serían impuestas por la legalidad, pueden terminar finalmente afectando los derechos que deben ser tutelados ${ }^{37}$. La diversificación de la tutela procesal trasunta en la adaptabilidad, plasticidad o adecuación de un proceso único a las características singulares de la controversia que a él se somete. Podría darse así la combinación de la especialización de los tribunales de justicia con sus tipos de procesos; bien un juez no especializado y la pluralidad de procesos especiales o, bien, un proceso general único con la posibilidad de flexibilizarlo para permitir su adecuación al tipo de controversia (sea a instancias tanto del tribunal como de las partes) ${ }^{38}$.

La especialización judicial y del procedimiento ha sido la tendencia tradicional en los distintos modelos procesales en Latinoamérica. Justamente a partir de la modulación o adecuación del proceso ordinario a

${ }^{33}$ Comp. Zagrebelsky (1997), p. 134; Settem (2016), pp. 195-202.

${ }^{34}$ Tronson (2016), pp. 183-202; Comp. Carratta, Taruffo (2015), pp. 250-258; Comp.Koller (2014), p. 49.

${ }^{35}$ Sorabji (2013), pp. 213-218; Tedoldi (2013), p. 380 y ss.; Trocker (2009), pp. 453508.

${ }^{36}$ Confr. Basilico (2010), pp. 737-743. Así bien sostienen Jorge Peyrano y María Eguren: "El proceso no puede volverse contra el propio justiciable ni imponerle la condena de sus tiempos ni favorecer la muerte de sus prerrogativas jurídicas... El proceso no puede ser cómplice, ni reliquia. La denominada 'urgencia intrínseca', confronta y mide al proceso en su versión tradicional y le denuncia sus falencias, le enrostra su insuficiencia y exhibe el vacío normativo a la hora de instrumentar soluciones ágiles y dinámicas adaptables a 'la medida de la urgencia'. En suma, revela la falta de 'medidas de urgencia' posibles de instrumentar una verdadera justicia 'a medida'”. Peyrano, Eguren (2006), p. 15.

${ }^{37}$ Véase Guinchard (2015), No 225; Comp. Giordano (2014), pp. 827-832.

${ }^{38}$ Véase en general CAdiet (2016), pp. 596-606; Dondi (2011), pp. 1-17. 
la diversificación de las tutelas requeridas por el Derecho Sustantivo se justificaron desde el punto de vista histórico y se justifica la existencia de las tutelas sumarias ${ }^{39}$.

La rigidez y el formalismo solo por legalismo prometen predictibilidad y un trato igualitario del justiciable, pero termina frustrándose, en la práctica, por no adecuarse a las particularidades de determinados derechos y $\operatorname{controversias}^{40}$. La rigidez no necesariamente se da cuando existe un tipo único de proceso sino, también, cuando es tal la cantidad de opciones procedimentales que el juez como el justiciable terminan desorientándose. Una salida es la flexibilidad y la ductilidad del proceso. Sí debe referirse a los imperativos de mejora internos a partir de una conducción procesal activa por el juez combinado con diálogo entre las partes y el tribunal, pudiendo adecuar una estructura común máxima para el caso particular ${ }^{41}$. Esa adecuación podría traducirse en la simplificación y, en su caso, en la implementación de las alternativas sumarias en cualquiera de las formas descritas $^{42}$. Ello no impide que se puedan preestablecer normativamente los supuestos a los que conviene o deba aplicarse el proceso sumario.

Podría verse como contradictorio requerir un juez activo en la dirección formal y material y, a su vez, instar la cooperación de las partes que justamente, lo dejará impedido de adecuar el procedimiento para el caso concreto ${ }^{43}$. También se verá en los informes como son escasos los modelos en los que se empodera a las partes para que puedan también "colaborar" a la simplificación del proceso mediante una negociación previa, esto es, un acuerdo, una convención o un contrato ${ }^{44}$. Parece razonable dar un espacio a la autonomía de la voluntad para generar un pret a porter procedimental ${ }^{45}$. Este tipo de contratación incentiva a "promover una mayor justicia ciudadana, una justicia más democrática bajo la tutela

${ }^{39}$ Para un examen comparado véase CARRATA (2012a), pp. 24-34.

${ }^{40}$ Comp. las visiones formalistas y materialistas según Tamanaha (2004), pp. 91-101.

${ }^{41}$ LegG, Higgins (2016), pp. 157-170.

${ }^{42}$ Comp. Cadiet (2016), pp. 596-600; Cfr. Carrata (2012a), pp. 18-25.

${ }^{43}$ Tradicional ha sido sostener que el modelo de juez en sistemas germanos y latinos (continental) sería más activo que el juez en modelos anglosajones. Que estos últimos serían prioritariamente adversariales. Pues puede verse que este criterio propuesto al menos en la adecuación del procedimiento para el caso acorde al derecho material discutido, no parece ser correcta. Una propuesta abierta y en la línea planteada en este artículo puede verse en CAPONI (2016), pp. 823-834; véase SEIDMAN (2016), pp. 20-23; en el mismo sentido comp. Gajardoni (2008), p. 112; Incluso, la distinción entre modelo procesal del Civil Law enfrentado con el del Cammon Law sería cada vez menos valida por el acercamiento de los modelos procesales STÜRner (2014), pp. 139, 271-297.

${ }^{44}$ Sobre la importancia del acuerdo de las partes sobre y para el proceso y procedimiento puede véase Hellwig (1910), pp. 41-79.

${ }^{45}$ CAPONi (2008), pp. 99-120; Müller (2014), p. 147 y ss. 
de un Estado mediador o facilitador en la búsqueda del equilibrio social, el a su vez, supera al Estado gendarme del siglo XIX y al de bienestar del siglo $\mathrm{XX}^{\prime 46}$. Parece importante poder combinar tanto el papel conductor y director del juez en la determinación del procedimiento con la cooperación o colaboración de las partes. Ello no se excluye de los casos donde sería aplicable la "sumariedad" en cualesquiera de sus manifestaciones propuestas $^{47}$. Existiendo la posibilidad de que sea aplicable fundado en urgencia de la tutela o evidencia del derecho a tutelar, no se ve obstáculo para la propuesta o iniciativa del tribunal con la implementación mediante la colaboración de las partes en un contradictorio pleno o diferido, en relación con una de las partes ${ }^{48}$.

\section{TÉRMINOS Y REALIDADES EN TORNO A LO “SUMARIO"}

Con lo "sumario" se hace referencia a un tipo de procedimiento o, bien, complementario más amigable en comparación con el "común, ordinario o general", altamente formalizado, complejo y lento. En otros informes se hace referencia a la (in) existente flexibilidad para simplificar un proceso único a instancia tanto de las partes como del tribunal. Finalmente se suele aludir al grado, nivel o profundidad del conocimiento exigido al juez para decidir, ello es con una menor exigencia probatoria ${ }^{49}$. Así, es posible relacionar las técnicas de flexibilización, simplificación y "sumariedad". Ada Pellegrini Grinover enuncia la necesidad de distinguir entre la tutela sumaria destinada a asegurar o a cautelar, de aquella cuya finalidad es satisfacer ${ }^{50}$. Los términos "tutelas sumarias" (tanto procesos sumarios como de cognición sumaria ${ }^{51}$ ) tienen una plurivocidad admirable. Puede, así hacerse referencia a:

i) una simplificación, abreviación o ambos para llegar más rápidamente a una decisión por oposición al proceso "ordinario";

ii) procesos donde el conocimiento del tribunal será "sumario", es decir, acotado a determinados aspectos, o con un estándar probatorio menos exigente;

${ }^{46}$ Cadiet (2012). pp. 6 y 35; Comp. Chizzini (2015), pp. 45-60.

${ }^{47}$ Comp. Davis, Hershroff (2011), pp. 507-564; Comp. Rhee (2009), pp. 523-530.

${ }^{48}$ Así Settem (2016) pp. 102-104, 67-68, 89-95; Da Rós Bodart (2015) pp. 107-112; Comp. Caponi (2016) pp. 823-832.

${ }^{49}$ Kramer (2014), pp. 220-221; comp. Watanabe (2004), pp. 684-690; Comp. Ferrari (2012), pp. 59-80.

${ }^{50}$ Pellegrini Grinover (2003) p. 107.

${ }^{51}$ El término 'cognición' refiere tanto al tipo de procedimiento (declarativo o de conocimiento) como al nivel de profundidad de conocimiento y estándar probatorio exigido para la decisión judicial, véase al respecto en general FERRI (2010), pp. 92-101. 
iii) a procesos donde la decisión es provisoria, teniendo una cierta instrumentalización de uno principal, por ejemplo, los procesos cautelares;

iv) finalmente una acepción mucho más amplia que permite incluir todos los anteriores bajo denominaciones genéricas, tales como "tutelas diferenciadas", los que combinan algunas de las acepciones anteriores. (iii) $)^{52}$.

Relacionado con algunas de las visiones antes mencionadas se encuentra lo "sumario" como una atemperación de lo "ordinario" o "general" para otorgar el debido resguardo a un derecho que es controvertido. En general, con el vocablo 'sumario' se identifica al proceso simplificado, breve, de mayor celeridad $^{53}$. Esa atemperación puede manifestarse como una menor exigencia probatoria o de profundización cognitiva para el tribunal o, bien, por la menor cantidad o complejidad de las etapas procesales ${ }^{54}$. Claro que estas dos visiones podrían confluir para caracterizar un tipo de proceso diferente al ordinario o general. La expresión 'sumario' se refiere tanto al ámbito de la cognición exigido para pronunciar una sentencia como a las modulaciones o adecuaciones procedimentales para ello ${ }^{55}$. Podría aludirse con 'sumario' tanto a las razones que justifican el nivel de menor exigencia en la cognición exigida para pronunciar determinada sentencia como a la simplificación procedimental ${ }^{56}$. En esta segunda acepción como proceso residual a uno general o común en algunos casos designado como "plenario abreviado" ${ }^{57} \mathrm{u}$ otras denominaciones (entre ellas "sumario") ${ }^{58}$.

${ }^{52}$ Véase una presentación general en CARrata (2012a), pp. 1-29.

${ }^{53}$ Berizonce, Bermejo, Sucunza (2015) Informe Argentina: "En tanto en la República Argentina cada Provincia puede dictar sus propias normas procesales, en cada una de esas jurisdicciones ese tipo de juicio puede tener una regulación diversa. Sin embargo, este es un proceso previsto en todos los ordenamientos formales locales, excepto en el Código Procesal Civil y Comercial de la Nación" "En el caso del Código Procesal Civil y Comercial de la Nación, se ha reformado suprimiendo el proceso sumario y dejando sólo al proceso ordinario, si bien con formas que anteriormente eran las del proceso sumario". Reforma, por cierto, no exenta de críticas.

${ }^{54}$ En este sentido puede verse el excelente trabajo de Della vedova (2013), pp. 173176; Comp. Ferri (2010), pp. 92-101.

${ }_{55}$ Priori Posada, Delgado Suárez (2016). Informe Perú; Comp. Da Rós Bodart (2015), pp. 38-44.

${ }^{56}$ En la misma línea Della vedova (2013), pp. 173-176; comp. Ferrari (2012), pp. 59-80.

${ }^{57}$ Comp. Fairen Guillen (1953) El juicio ordinario y los plenarios rápidos: los defectos en la recepción del Derecho Procesal común: sus causas y consecuencias en doctrina y legislación actuales, primera parte.

${ }^{58}$ Ya lo sostenía con corrección Juan Monroy Palacios: "en los procesos de tutela jurisdiccional de urgencia constituyen la sumarización cognitiva y la sumarización procedimental. La primera alude a la posibilidad de que se dicten resoluciones de actuación inmediata, sin necesidad de llegar a un conocimiento pleno del conflicto; la segunda está 
Veamos algunos usos del término, de acuerdo con los informes nacionales.

a. En algunos ordenamientos se hace hincapié en la menor profundización de la cognición judicial por oposición al conocimiento pleno y exhaustivo. El término 'sumario' en la Ley de Enjuiciamiento Civil española no se emplea como sinónimo de 'rapidez', 'celeridad' o 'inmediación'59. Cuando se usan expresiones como 'verbal' y 'sumario' se hace con un significado especial. Así, para la tutela de la tenencia, posesión pacífica o el ejercicio de un derecho real sobre un bien inmueble o, bien, cuando deba decidirse sobre algunos supuestos de incumplimiento contractual se conoce mediante un proceso verbal para otorgar una tutela sumaria ${ }^{60}$. No hay oposición entre lo sumario y lo ordinario, sino que la distinción se reduce entre "juicio ordinario" y "verbal". Este se caracteriza por su simplificación y se señala expresamente cuando se aplica. Los criterios empleados son la materia (como criterio de especialización y, por ende, preferente) o la cuantía ${ }^{61}$. Se deciden en juicio verbal algunas materias y -de no ser algunas de estas- siempre y cuando no excedan de determinado monto. Deben sumarse a estos procesos aquellos que tienen por objetivo inmediato la tutela del crédito mediante la obtención expedita de un título ejecutivo, como lo son el proceso cambiario y el monitorio ${ }^{62}$. En resumen, la LEC distingue entre un proceso ordinario y otro verbal, no contemplando un tratamiento diferenciado para el sumario ${ }^{63}$.

El Código General del Proceso de Uruguay prevé, además de un proceso "ordinario", alternativas a partir del Derecho Sustantivo a tutelarse:

"El CGP, dentro de los procesos de conocimiento, además del proceso ordinario, prevé otras dos estructuras: el proceso extraordinario (arts. 346 a 349) y el proceso de estructura monitoria (arts. 351 a 370) que son dos especies de un mismo género común que de acuerdo a la expresión tradicional se clasifican como procesos

referida a la abreviación de los plazos, limitación de los medios probatorios, concentración de los actos procesales y otras técnicas". Monroy Palacios (2004), pp. 194-195.

${ }^{59}$ Gascón Inchausti, García-Casas (2015).

${ }^{60}$ Así, la referencia contenida en el art. $250 \mathrm{~N}^{\mathrm{os}} 10$ y 11 Ley de Enjuiciamiento Civil, véase Gascón Inchausti, García-Casas (2015); Armenta Deu, Oromí Vall-Llovera, Pereira Puigvert (2015). Informe España.

${ }^{61}$ Ibid.

${ }^{62}$ Ibid.

${ }^{63}$ Gascón Inchausti, García-Casas (2015). "Sin embargo, incluye dentro del ámbito del 'juicio verbal' ciertos procedimientos que son sumarios y que se resolverán, como se ha indicado previamente, mediante una sentencia que carezca de fuerza de 'cosa juzgada"”. 
sumarios, si bien como hemos anotado en la respuesta anterior, ese término no es utilizado en nuestro CGP" ${ }^{64}$.

Asimismo, diversas leyes especiales prevén una tramitación simplificada ${ }^{65}$. El uso de la voz ‘sumario' se reduce al grado de exigencia probatoria, por ejemplo, para la concesión de una medida cautelar ${ }^{66}$. Los extraordinarios y aquellos con estructura monitoria tienen una mayor simplificación y concentración para otorgar una solución expedita a determinados casos a partir de la pretensión que se hace valer, en comparación al proceso "ordinario". Expresamente la ley determina los supuestos de aplicación:

"Como podemos apreciar, analizando las pretensiones a las que el CGP le asigna esta estructura, vemos que los objetos tienen las características propias de la categoría de procesos sumarios como ser: la urgencia (procesos alimentarios), simplicidad (procesos de familia, guarda, visita, etc.) y la simplificación (procesos posesorios y cuasi posesorios)" ${ }^{67}$.

En el caso de la "estructura monitoria", esta también es susceptible de aplicarse a casos específicos a partir de la "certeza inicial o a la simplicidad que hacen presuponer bajos niveles de oposición" 68 . También, se debe mencionar que existe un proceso para aquellas causas de menor cuantía con simplificación en su tramitación ${ }^{69}$.

Por su parte, el Código de Processo Civil de Portugal (2013) hace uso de las expresiones 'sumário', 'sumária' e "sumariamente' con múltiples sentidos. Por lo pronto, se debe aclarar que en el actual Código en el proceso declarativo o de conocimiento no se distingue entre lo 'ordinario' y lo 'sumario', pues existe una única modalidad ${ }^{70}$. Con esta salvedad los términos se emplean:

i) para aludir a una de las formas del proceso de ejecución para el pago de una cuantía cierta;

${ }^{64}$ Valentin, Hegedus (2015). Informe del Uruguay.

${ }^{65} \mathrm{Ibid}$.

${ }^{66}$ Ibid:: "En materia de proceso cautelar, como es lo habitual en derecho comparado, a los efectos de adoptarse una medida cautelar el CGP, art. 312, exige que la existencia del derecho y el peligro de lesión o frustración, “deberán justificarse sumariamente". Por su parte, el art. 316, también en sede de medidas cautelares requiere solo la acreditación sumaria de ciertas circunstancias que ameriten una modificación de medida”.

${ }^{67} \mathrm{Ibid}$.

${ }^{68} \mathrm{Ibid}$.

${ }^{69} \mathrm{Ibid}$.

${ }^{70}$ Lebre de Freitas, Teixeira de Sousa, Soares Pereira (2015). Informe Portugal. 
ii bien a la decisión pronunciada por un tribunal que conoce de un recurso y decide mediante uno de sus miembros (cuando existe sobre la materia una jurisprudencia constante);

iii) para referirse a un nivel de convicción que genera una prueba, inferior al nivel de verdad;

iv) ya sea para aludir a una simplificación en la apreciación de los hechos o en la fundamentación de una sentencia ${ }^{71}$.

En el proceso ejecutivo para el pago de una obligación cuya cuantía es indubitada es posible distinguir entre un proceso ordinario y otro sumario, según el tipo de título ejecutivo. Vale aclarar que, sumado a la existencia de un único tipo de proceso declarativo, se prevé que en aquellas causas de hasta un determinado monto, el juez pueda simplificar o agilizar la tramitación. Fuera del $C P C$, a través de una ley especial se regula una acción declarativa especial para las obligaciones contractuales pecuniarias de hasta una determinada cuantía. Además, rige en Portugal como Estado miembro de la UE el reglamento (CE) No 861/2007 para aquellas acciones de una cuantía que no exceda de los $€ 2.000^{72}$.

Finalmente, en esta línea puede mencionarse a $\mathrm{Brasil}^{73}$. En el proceso civil brasileño se usa el término 'sumario' en dos sentidos muy diferentes:

i) en primer lugar, para referirse a los niveles de profundidad de la cognición judicial para aludir a aquella que no llega a ser completa o exhaustiva ${ }^{74}$. Así, una decisión pronunciada con este grado de cognición es mutable y no genera cosa juzgada;

ii) En el antiguo Código Procesal Civil de 1973 se distinguía entre un proceso ordinario y otro sumario. Este es un procedimiento más simplificado y aplicable a determinados tipos de controversias, ya sea por su cuantía, ya sea por su menor complejidad.

El Nuevo Código de Processo Civil, aprobado en el año 2015 establece un procedimiento común eliminando aquella distinción. No obstante ello, existe en Brasil un procedimiento para las controversias de menor cuantía, denominado "sumarísimo" (ley No 9.099/1995), que, además, es de la competencia de los juzgados especiales federales o del Estado que corresponda ${ }^{75}$.

b. Se acude en otros modelos a la distinción entre el proceso "extraordinario" (que comprende uno simplificado en algunos casos llamado

${ }^{71}$ Lebre de Freitas, Teixeira de Sousa, Soares Pereira (2015).

${ }^{72}$ Ibid.

${ }^{73} \mathrm{El}$ importante desarrollo y aporte que hizo el Derecho brasileño puede verse en MARINONI (2013), pp. 1353-1367.

${ }^{74}$ Véase Ferres da Silva Ribeiro (2015), pp. 73-81.

${ }^{75}$ Cruz Arenhart, Osna (2015). Informe Brasil. 
sumario) por oposición al otro "ordinario"76. El nuevo Código Procesal Civil boliviano (2016) no emplea la voz 'sumario', no obstante, regula una alternativa más simplificada al 'ordinario', que denomina 'extraordinario'77.

En el nuevo Código de Procedimiento Civil del Ecuador (2015) con 'sumario' o 'procesos sumarios' se designan aquellos que por su naturaleza tienen una tramitación que se caracteriza por su mayor celeridad:

"Este término es empleado para designar o identificar procesos que, en teoría, deben ser tramitados con mayor celeridad y prescindiendo de ciertas formalidades y etapas presentes en los juicios ordinarios" $"$.

La regla es el proceso ordinario, siendo lo "sumario" apenas una simplificación de aquel.

En Perú los procesos sumarios tienen la misma estructura y sistematización que el proceso de conocimiento pleno, pero con la consiguiente reducción de los tiempos, la simplificación procedimental y la reducción de la cognición coherente con la menor complejidad de la materia discutida $^{79}$. En este país la voz 'tutela sumaria' se utiliza en el ámbito doctrinario, jurisprudencial y normativo haciéndose referencia al "proceso sumarísimo" 80 . Con esta expresión se alude a los procedimientos típicos y atípicos destinados a tutelar determinados derechos "de menor complejidad probatoria" ${ }^{2}$.

Por su lado, en la República Dominicana se usa la expresión 'sumario' en varios sentidos sin aludir con ello a un tipo de proceso específico ${ }^{82}$.

${ }^{76}$ Incluso, corresponde recordar que en Argentina, el $C P C P B A$ existe el proceso suma-rio (art. 320 del $C P C P B A$ ), el proceso ordinario (art. 319, 838, 484 a 495, entre otros del $C P C C B A$ ) y el sumarísimo (art. $321 \operatorname{del} C P C B A$ ). Así, según Berizonce, Bermejo, Sucunza (2015). Informe Argentina.

${ }^{77}$ Villarroel Bustios, Mostajo Barrios (2015) Informe Bolivia. "El código anterior (1976) regulaba el proceso sumario. En el antiguo CPC incluso se contemplaba la posibilidad de que las partes convineran la aplicación del proceso sumario. Nada se dice en el nuevo con relación al 'extraordinario'. por cierto esta terminología también la emplea el Código de Procedimiento Civil de Chile del año 1903 (arts. $2^{\circ}$ y $3^{\circ}$ ) sin mayor referencia que incluir en lo 'ordinario' la tramitación común establecida por la ley por oposición a disposiciones 'especiales'”.

${ }^{78}$ FALCONi Puig (2015). Informe Ecuador.

${ }^{79}$ Priori Posada, Delgado Suárez (2015). Informe Perú.

${ }^{80} \mathrm{Ibid}$.

${ }^{81}$ Ibid.

${ }^{82}$ Existe ya en el Congreso Nacional un anteproyecto código procesal civil, en el Libro XI se regulan procedimientos especiales, entre los cuales está el sumario. "Este procedimiento es aplicable a los diferendos comerciales, a las acciones en pago de sumas de dinero y al pago de indemnizaciones de daños y perjuicios". CRuCETA (2015). Informe República Dominicana. 
Existen, además, los procesos de menor cuantía ante la justicia de paz, con una tramitación rápida, denominados 'referimiento'. En este tipo de procedimiento

“el juez es un juez más de apariencia que de certeza, por lo que pudiera afirmarse que existe cierta flexibilidad en el estándar probatorio, ya que dicho procedimiento tiene lugar en caso de urgencia ante un peligro inminente" ${ }^{83}$.

En el proceso civil venezolano no existe un proceso denominado como tal, sino que uno de tramitación breve para las controversias de hasta un determinado monto y algunos tipos especiales de controversias relacionadas con los bienes inmuebles ${ }^{84}$.

En Chile se regula el "juicio sumario" entre los procesos especiales por oposición al ordinario. Se aplica en aquellos casos en los que la acción deducida requiera de una tramitación rápida para garantizar su eficacia y en determinados tipo de acciones que deben tramitarse de ese modo (algunos mencionados en el mismo Código, otros en leyes especiales) ${ }^{85}$. Asimismo, hay otros procedimientos especiales con una tramitación más simplificada que el juicio declarativo ordinario (incluso supuestos de menor y hasta mínima cuantía) $)^{86}$.

${ }^{83}$ Cruceta (2015). Informe República Dominicana.

84 "Hay un proyecto de reforma que establece un proceso abreviado para controversias "que por su naturaleza puedan debatirse en una única audiencia", además se establece que un mismo tribunal tiene las atribuciones para sustanciar, juzgar, ejecutar y actuar como mediador. Además de esta disposición abierta esos tribunales conocerán mediante el procedimiento breve de determinadas materias establecidas en el referido proyecto de código o en leyes especiales" (Rivera y colaboradores (OchoA, Martinez, Paz, Camero, Martinez) (2015) Informe Venezuela).

${ }^{85}$ Así, por ejemplo, dada la tramitación simplificada la jurisprudencia no admite la demanda reconvencional por el demandado, ya que ello "complejizaría" el proceso. Así lo ha decidido la Corte de Apelaciones de Valparaíso, en cuanto a la improcedencia de la reconvención en juicio sumario 12 de diciembre de 2001, rol No 3399.

${ }^{86}$ Letelier, Tavolari, Valenzuela (2015). Informe Chile; la regulación de la tutela cautelar se la hace bajo la designación restringida de "medidas precautorias", aunque la designación ya ha sido superada por "cautelar" en la regulación penal, ambiental, familia y laboral, véase MARín GonZÁlez (2016), pp. 50-87. En Chile conviene advertir que en materia de justicia de familia existen un procedimiento de tutela de los derechos como "medidas de protección" que asumen la calidad de cautelares sumarios principal con decisión provisoria. Además, en otra área reformada como la laboral los derechos fundamentales de los trabajadores en determinadas circunstancias pueden ser resguardados por lo que se denomina "procedimiento de tutela laboral", que tiene simplificación y una gran efectividad. Dos áreas de reforma de la justicia que contrastan con la ya anacrónica justicia civil. 
En Cuba la reforma del año 1973 contempló dos tipos de procesos de conocimiento: el ordinario y el sumario, actualmente regulados en la vigente Ley de Procedimiento Civil, Administrativo, Laboral y Económico. Se lo caracteriza como:
"un modelo de cognición reducida, encaminado a resolver pre- tensiones de menor envergadura, razón por la cual las decisiones que se obtienen en este tipo de proceso, no adquieren el efecto de la cosa juzgada material" $" 87$.

En Argentina (con las reservas del sistema Federal sobre la base del cual existen tantos códigos como Estados provinciales, además de un código para las materias federales) existe una combinación de los usos del término en todos los sentidos referidos hasta ahora $^{88} \mathrm{e}$, incluso, en algunos casos hay procedimientos más simplificados y rápidos ${ }^{89}$.

${ }^{87}$ Mendoza DíAz, Juan (2015). Informe Cuba: "La propia tramitación del modelo procesal sumario, condiciona que la cognición judicial sea limitada, razón por la cual la misma Ley deja sentado la carencia de los efectos de la cosa juzgada material para los fallos a los que se arribe en este tipo de procesos. No es la profundidad de la prueba lo 154 que condiciona la naturaleza cognoscitiva del tribunal, porque el proceso ordinario tiene un carácter supletorio para el sumario en cuanto a la práctica de los diferentes medios de prueba y no existe limitación sobre la extensión y la profundidad de la prueba que se practique. La eventual apertura posterior de la litis sobre el mismo tema obedece a la naturaleza cambiante de los asuntos que preceptivamente la Ley ha colocado bajo el prisma de este modelo procesal. En el supuesto previsto en el apartado 1 del artículo 358, por la naturaleza de este tipo de reclamación, la sentencia que se adopte tiene el carácter de perpetua y disfruta por ello del efecto de la cosa juzgada material".

${ }^{88}$ Berizonce, Bermejo, Sucunza (2015). Informe Argentina: "El fenómeno procesal más notable entre nosotros ha sido la evolución desde las tradicionales medidas cautelares hacia el reconocimiento de la operatividad, junto a aquéllas, de una categoría diversa, que es la que comprende las denominadas cautelas materiales o tutelas anticipadas y definitorias articuladas mediante los procedimientos sumarios tendientes a la satisfacción del derecho material en disputa Por ejemplo, en el CPC de La Pampa se prevé una tutela anticipada, la denominada 'autosatisfactiva', de creación doctrinaria y acogimiento jurisprudencial en el orden nacional; asimismo, prevé procesos de estructura monitoria (arts. 231 bis, 463 y conc.). En general, en el derecho argentino, la tutela sumaria no sustituye al proceso común (u ordinario), sino que tan solo lo abrevia. Así, la anticipación de la tutela requiere la posterior sentencia de mérito. El juicio seguirá hasta su finalización; naturalmente el pronunciamiento final podrá dejar sin efecto las medidas provisionales, si durante la secuela del proceso hubieren cambiado las condiciones tenidas en consideración para otorgarlas".

${ }^{89}$ Incluso, se contemplan casos con mayor ("sumarísimo") o menor ("sumario") simplificación. Berizonce, Bermejo, Sucunza (2015). Informe Argentina enuncia que: "En forma independiente los códigos procesales regulan al proceso sumarísimo, como la forma más breve del género de los procesos de conocimiento, reservado para excepcionales supuestos. La denominación de 'verbal' no está unido indefectiblemente al proceso sumario, pues éste 


\section{ProcedimiEntos SIMPLIFICAdos Y TÉCNICA SUMARIA}

La existencia de una técnica sumaria puede concentrarse en procedimientos simplificados, donde puede arribarse a decisiones definitivas. Surgen entonces la interrogante sobre los tipos de controversias que pueden (o deben) tramitarse y el papel asignable al legislador, juez y partes el ámbito de aplicación dicha opción procedimental. Si es posible optar por las partes tanto como ser indicado por el juez un tipo de proceso diferente al ordinario o general o, bien, no existiendo sino un tipo de proceso puede ser simplificado, entonces estamos frente a la rigidez o a la flexibilidad procesa $^{90}$. La combinación de la cuantía con las materias consideradas como menos "complejas" suele sustentar la procedencia de la "sumariedad". Así en muchos casos existe una limitación a la libre elección de las partes por este tipo de proceso ${ }^{91}$. Incluso, se argumenta que ello no sería disponible por las partes, so consecuencia de vulnerarse el debido proceso legal ${ }^{92}$.

puede sustanciarse con preeminencia de lo escrito -como ocurre, en general, para el debate de los temas civiles y comerciales- o de lo oral o verbal (por audiencias) Sin embargo, en el caso de Código de San Juan, se prevé que el sumario podrá ser verbal o escrito".

${ }^{90}$ Véase una visión contemporánea general y fundamental en este sentido en CADIET (2016), pp. 596-606; Comp. CAPONI (2016), pp. 823-834.

${ }^{91}$ Como aclaración debe poder adaptarse un tipo de proceso u otro (sea que se prohíba la convencionalidad tanto como pueda el juez determinarlo) o, bien, algo menos desafiante como que las partes puedan acordar los plazos o simplificar la tramitación son niveles y formas de mayor o menor flexibilidad. Lo segundo (disposición sobre el procedimiento en los plazos o las formas) se valora normalmente como positivo y se ha permitido en la mayoría de los modelos procesales. Lo primero es lo mirado con reservas en muchos de los ordenamientos. Así valga la aclaración de Mendoza DíAz (2015). Informe Cuba: "En nuestro medio los modelos procesales están concebidos para que agoten la estructura que el legislador les concibió, lo cual no es óbice para que las partes puedan renunciar, tácita o expresamente, a la realización de determinados actos, lo que puede traer aparejada una solución más acelerada del proceso, pero sin que ello implique un cambio de la naturaleza originaria del proceso ordinario".

${ }^{2}$ Así, en Argentina se habla de "orden público procesal indisponible". BERIzonce, Bermejo, Sucunza (2015). Informe Argentina. En el caso de Uruguay se sostiene: "En nuestro sistema de derecho, las partes no pueden disponer de las formas procesales en tanto las mismas están establecidas legalmente, principio de legalidad de las formas por oposición al sistema de las formas judiciales. Nuestra Constitución en su art. 18 dispone que las leyes fijarán el orden y las formalidades de los juicios, y el art. 23, por su parte, consagra la responsabilidad de los jueces por separarse del orden en el proceder que en la ley se establezca.. En relación a la pregunta que se formula, estas normas, en relación a las partes, excluyen la posibilidad de que las mismas de común acuerdo puedan modificarlas. El art. 16 del $C G P$, recoge este principio de legalidad al establecer que los sujetos del proceso no pueden acordar por anticipado, dejar sin efecto las normas procesales, salvo en el proceso arbitral". Valentin, Hegedus (2015). Informe de Uruguay. 


\section{Proceso Civil:}

el litigio individual

El CGP de Uruguay excluye toda posibilidad de convencionalidad ${ }^{93}$. Un argumento interesante en este sentido es lo sostenido el informe de Perú:

"El fundamento para tal opción es la necesidad de que la tutela jurisdiccional sea adecuada al derecho material inclusive cuando las partes, en uso de su iniciativa privada, hayan optado por conveniente solicitar la tramitación de una determinada pretensión en una vía que jurídicamente no corresponde" ${ }^{94}$.

Como ejemplo de cierta flexibilidad puede mencionarse el caso de Chile. Un código de inicios del siglo xx aún no reformado que contempla la posibilidad que las partes puedan acordar tácitamente lo que se denomina "substitución del procedimiento". Ello se verifica en el caso de aquel que demandó en juicio ordinario solicite que se prosiga la tramitación mediante las reglas del juicio sumario y no se oponga a ello el demandado: "Ello siempre que se trate de una acción que por su naturaleza requiera una tramitación rápida" 95 .

156 En el sistema procesal del Ecuador se permite que las partes puedan acordar la tramitación verbal y sumaria. A esta posibilidad se agregan los casos donde, a través de leyes especiales o en los Códigos de Procedimiento Civil, como en el General de Procesos (con entrada en vigencia en el año 2016), se contemplan supuestos de tramitación sumaria obligatoria ${ }^{96}$. La posibilidad de acuerdo se reduce a lo "verbal y sumario". Lo verbal se refiere a características tales como la concentración y la audiencia, mientras que lo "sumario" tiene relación con la celeridad del procedimiento por su simplificación en comparación con el proceso general u "ordinario". Se entiende que, al guardar silencio el Código Orgánico General de Procesos sobre la posibilidad de convenir la tramitación "sumaria", ello no sería posible ${ }^{97}$.

${ }^{93}$ Valentin, Hegedus (2015), Informe del Uruguay.

${ }^{94}$ Así en Priori Posada, Delgado Suárez (2015). Informe Perú. Se sostiene, además, que: "De tal forma, considerando el poder directriz del proceso del cual el juez es titular, sumado al derecho fundamental a la tutela jurisdiccional efectiva, la posibilidad de adecuar o adaptar o corregir la vía procedimental propuesta por las partes es una consecuencia lógica de la moldura del procedimiento al derecho que viene siendo discutido en el mismo, por un respeto mínimo al objeto controvertido en un determinado procedimiento".

${ }^{95}$ Letellier, Tavolari, Valenzuela (2015). Informe Chile.

${ }^{96}$ FALCONI PUig (2015). Informe Ecuador.

${ }^{97}$ Ibid. 
Se mencionan como ejemplos de "disponibilidad" del proceso y de la libre elección por las partes al acuerdo arbitral, que al ser un contrato o convención se sustenta en la autonomía de la voluntad. La posibilidad del arbitraje no parece ser objeto de crítica y cabría bajo los parámetros de la "legalidad". No parece criticable que, siendo el objeto del proceso disponible, sea posible sustraerlo del proceso judicial para someterlo a un tribunal y a un proceso arbitral ${ }^{98}$. Ahora bien, resulta a lo menos curioso que un acuerdo de menor entidad como sería la posibilidad de optar por un tipo de proceso alternativo al general o con mecanismos destinados a su flexibilización, sea objetable solo fundándose en el debido proceso ${ }^{99}$. Por un lado, hay flexibilidad (inclusión de cláusulas abiertas) o casos expresos en los que el juez puede aplicar una tramitación ordinaria o lo sumaria ${ }^{100}$. Por el otro, la rigidez que parece ser la regla que impide a las partes y al juez poder decidir el proceso para un caso determinado. Ello puede atemperarse con la posibilidad de la simplificación y la concentración del procedimiento $^{101}$. Lo cierto es que la "sumariedad" meramente procedimental parece más bien replicar a lo ordinario y solo reducir el tiempo de duración de un proceso ${ }^{102}$. En el Código portugués, el juez dispone de un poder de gestión procesal para adoptar -con audiencia previa de las partes- aquellas medidas de simplificación que tiendan a la solución del litigio en un plazo razonable. El juez podría ordenar una tramitación que simplifique el procedimiento declarativo único existente. Las partes no pueden escoger el tipo de proceso (ya que es único), tampoco pueden disponer de la tramitación preestablecida ${ }^{103}$. Vale aclarar que además de la existencia de un único tipo de proceso declarativo, se prevé que en aquella causas de hasta un determinado monto, el juez pueda simplificar o agilizar la tramitación ${ }^{104}$.

${ }^{98}$ Comp. Punzi (2016), pp. 1-16.

${ }^{99}$ Chizzini (2015), pp. 45-60.

${ }^{100}$ Así, por ejemplo, en algunas provincias de Argentina, en el Informe de Argentina: "El Código Procesal Civil y Comercial de Corrientes, agrega a ello que cuando la controversia versare sobre derechos que no sean apreciables en dinero, o existan dudas sobre el valor reclamado y no correspondiere el proceso sumario o sumarísimo, o un proceso especial, el juez determinará el tipo de proceso aplicable. En estos casos, así como en todos aquellos en que este Código autoriza al juez a fijar la vía de confrontación, la resolución será irrecurrible y dentro de los cinco días de notificada personalmente o por cédula la providencia que lo fije, el actor podrá ajustar la demanda a ese tipo de proceso. En la Provincia del Chaco, el Código Procesal también prevé que la controversia se tramitará por juicio sumario o sumarísimo, según lo determine el juez atendiendo a la complejidad de la contienda". Berizonce, Bermejo, Sucunza (2015). Informe Argentina.

${ }^{101}$ Comp. Los Santos (2012), p. 1062 y ss.

${ }^{102}$ Comp. Cadiet (2007), pp. 57-78; Carrata (2012a), pp. 5-12.

${ }^{103}$ Lebre de Freitas, Teixeira de Sousa, Soares Pereira (2015). Informe Portugal. ${ }^{104}$ Ibid. 
En la Ley de Enjuiciamiento Civil española no se admiten los pactos entre las partes ni siquiera para simplificar el procedimiento: "El sistema resulta, por tanto, tremendamente rígido" ${ }^{105}$. Mediante una reciente reforma se modificó la tramitación del juicio verbal, pudiendo las partes, ahora, renunciar al trámite de la vista, siempre que esto lo estime pertinente el tribunal ${ }^{106}$. Ello, no obstante, no debe verse como el resultado de un acuerdo, ya que es una facultad de las partes solicitarlo cuando no practicarán diligencias de prueba que requieran de la inmediación ${ }^{107}$.

Aquí debe mencionarse el modelo procesal civil de Brasil. Ni en el antiguo ni en el nuevo modelo procesal las partes pueden escoger el tipo de procedimiento. No obstante, el Código de 2015 incorpora una importante innovación en el art. 190, la posibilidad de que las partes celebren acuerdos procesales. Si el proceso versa sobre aquellas materias en las que las partes pueden disponer y llegar a una autocomposición, también pueden convenir las modificaciones al procedimiento antes de su inicio o durante su tramitación. El juez puede controlar el acuerdo de oficio o a requerimiento de parte ${ }^{108}$. Las partes o el juez pueden, además, acordar el calendario procesal y poder así planificar. Sí, existe posibilidad de optar para el demandante relacionado con el procedimiento ante los juzgados especiales estatales. Así, podría interponer la demanda ante un juzgado especial estatal o ante la justicia ordinaria y, por ende, someterse al procedimiento común. Esta interpretación surge de la diferente regulación

105 "no pueden simplificar ciertas etapas del procedimiento, ni pueden configurar fases de alegación y prueba distintas de las legalmente previstas, ni pueden alterar los plazos procesales que dispone la LEC". Gascón InChausti, García-CASAS (2015).

${ }^{106}$ Por la ley 42/2015, de 5 de octubre de 2015, de reforma de la Ley de Enjuiciamiento Civil española. Se debe mencionar, además, la reforma por “... la Ley 15/2015, de 2 de julio, de Jurisdicción Voluntaria. En el Título IX de esta ley se contiene el régimen jurídico del acto de conciliación de forma completa, trasladando y actualizando a esta ley lo hasta ahora establecido en la anterior Ley de Enjuiciamiento Civil (no la actual), sin perjuicio de que, en ejercicio de su autonomía de la voluntad, las personas tengan la posibilidad de obtener acuerdos en aquellos asuntos de su interés de carácter disponible, a través de otros cauces, por su sola actuación o mediante la intervención de otros intermediarios u operadores jurídicos, como los Notarios o Registradores". Armenta Deu, Oromí Vallllovera, Pereira Puigvert (2015). Informe España. Complementa al respecto Marcos Francisco (2016), pp. 8-12.

${ }^{107}$ Gascón Inchausti, García-Casas (2015). Informe España.

${ }^{108}$ Así "Art. 190. Versando o processo sobre direitos que admitam autocomposição, é lícito às partes plenamente capazes estipular mudanças no procedimento para ajustá-lo às especificidades da causa e convencionar sobre os seus ônus, poderes, faculdades e deveres processuais, antes ou durante o processo. Parágrafo único. De ofício ou a requerimento, o juiz controlará a validade das convenções previstas neste artigo, recusando-lhes aplicação somente nos casos de nulidade ou de inserção abusiva em contrato de adesão ou em que alguma parte se encontre em manifesta situação de vulnerabilidade". 
de los juzgados especiales federales y de los estatales ${ }^{109}$. A partir de ello, se sostiene que es una facultad del demandante ${ }^{110}$.

Importante desarrollo se ha dado a la tutela sumaria en materia de justicia de familia, niños y adolescentes ${ }^{111}$. En materia de tutela de los derechos del niño y el resguardo en la violencia familiar se han desarrollado en los modelos latinoamericanos procedimientos con celeridad ante la grave amenaza o vulneración. Aun, se minimizan requisitos de fundamentación, permitiendo la argumentación simplificada ante casos similares $^{112}$. Ha sido un paradigma la jurisprudencia en los tribunales chilenos al respecto ${ }^{113}$. Es, incluso, en esta materia donde, ante falta de regulación procesos como los que se verán en la sección que viene, se acude a acciones constitucionales de tutela de derechos fundamentales con efectos colecti-

${ }^{109}$ En relación con ello, Cruz Arenhart, Osna (2015). Informe Brasil sostiene: "Identificando a questão posta em relação ao procedimento dos Juizados Especiais, é preciso traçar uma distinção entre aqueles de ordem Federal e aqueles de instância Estadual. É que aqui, ao contrário do que ocorre na maior parte do procedimento, há uma distinção no tratamento legal. Para compreender o problema, deve-se inicialmente mencionar o art. $3^{\circ}, \S 3^{\circ}$, da Lei $\mathrm{N}^{\circ} 10.259 / 2001$, responsável por regular a atuação dos Juizados Especiais Federais: 'Art. $3^{\circ}$ Compete ao Juizado Especial Federal Cível processar, conciliar e julgar causas de competência da Justiça Federal até o valor de sessenta salários mínimos, bem como executar as suas sentenças.(...) $\S 3^{\circ}$ No foro onde estiver instalada Vara do Juizado Especial, a sua competência é absoluta'. Ainda que a disposição seja confusa, seu teor tem recebido aplicação literal. Assim, em qualquer foro onde existisse Juizado Especial Federal constituído, seria ele o único responsável por apreciar 'causas de competência da Justiça Federal até o valor de sessenta salários mínimos'. Nessas hipóteses, caso a demanda houvesse sido proposta perante a instância ordinária, seria preciso obstar o seu trâmite - priorizando-se, quando possível, sua remessa aos Juizados. De outro lado, no que se refere à atuação dos Juizados Especiais Estaduais, a situação é diversa. E isso porque, nesse âmbito, não existe regra com conteúdo análogo àquela acima descrita”.

${ }^{110}$ Así sostiene el FONAJE: "O exercício do direito de ação no Juizado Especial Cível é facultativo para o autor”. Citado por Cruz Arenhart, Osna (2015).

${ }^{111}$ Así se resalta ello en algunos informes nacionales Berizonce, Bermejo, Sucunza (2015). Informe Argentina; FalConi Puig (2015). Informe Ecuador; Villarroel Bustios, Mostajo Barrios (2015). Informe Bolivia; Valentín, Hegedus (2015). Informe del Uruguay. Acá coincidente con esta visión el fallo del Tribunal Superior Boliviano sobre la necesidad de acudir a un procedimiento sumario en casos de derechos de niños niñas y adolescentes Sentencia Constitucional 1889/2011-R Sucre, 7 de noviembre de 2011 (2011-23059-47-AL).

${ }^{112}$ Véanse los criterios esbozados en las decisiones de estos dos tribunales en relación con decisiones aplicando medidas de "protección”, Corte de Apelaciones de Punta Arenas, 27 de octubre de 2011, rol 88-2011 y Corte de Apelaciones de Coyhaique, 21 de enero de 2014, rol 41-2013.

${ }^{113}$ Así, Corte de Apelaciones de Punta Arenas, 4 de octubre de 2012, rol 103-2012 con especial consideración al interés superior del niño lactante en este caso para ordenar que continúe bajo el cuidado de la madre. Comp., por cierto, del mismo tribunal 7 de noviembre de 2012, rol N¹04-012 en otra causa para justificar la aplicación de las medidas en el tiempo con razonabilidad. 
vos. En el mismo sentido la incorporación y aplicación directa cada vez más aplicada del Derecho Internacional en materia de Niños flexibiliza las medidas que se ordenan ${ }^{114}$, esto último, también, ha permitido verdaderos procesos colectivos (no institucionalizados) al alero de acciones y proceso para tutela de derechos fundamentales ${ }^{115}$.

\section{Los procesos colectivos}

Son un interesante ámbito para evaluar las tutelas sumarias, siendo que en Iberoamérica la regulación de las tutelas colectivas constituye, en algunos casos, una novedad aún no contemplada legislativamente (tiene márgenes de creación pretoriana) ${ }^{116}$. La utilidad para esta investigación está dada, por un lado, por la complejidad de los interesados que intervienen como de las materias tratadas que abarcan (desde Derecho del Consumo hasta Derecho Ambiental y tutela de derechos fundamentales) donde aplicar los criterios de tutela sumaria como simplificación del litigio individual podría resultar difícil dada la necesidad de abrir la participación como condición de legitimidad mucho más exigente ${ }^{117}$. Por otro lado, suelen siempre incluirse o complementarse tutelas sumarias cautelares que puedan resguardar los derechos discutidos y así el uso del negocio o acuerdo

160 procesal tiene mayor aplicación. En común hay una falta de regulación sistemática y estructural que genera algunas disfuncionalidades en relación con la tutela de los derechos colectivos ${ }^{118}$. Más aún cuando se trata

${ }^{114}$ Comp., por cierto, el fallo de la Excelentísima Corte Suprema de Justicia de Chile, causa rol 5715-2012.

${ }^{115}$ Como ejemplo de ello pueden mencionarse algunos casos, por ejemplo, en Chile con el uso del llamado recurso de protección la propia Corte Suprema ha ordenado la reincorporación de alumnos expulsados a los establecimientos educacionales tras participar en movilizaciones estudiantiles, fundándose en la violación al derecho de defensa (rol 57152012 y 3179-2012 de la Excma. Corte Suprema de Justicia); visión contraria adoptada por otros tribunales del país a no sobredimensionar el recurso de protección en desmedro de los tribunales y procedimientos especiales para ello, así Se reconoce que en el caso que lo ha sido, la segunda instancia rechaza el recurso instando a las partes solicitar lo que "corresponda" a los juzgados de familia, declarando inadmisible el recurso de protección; y en este mismo sentido lo decidido por la Corte de Apelaciones de San Miguel, 15 de mayo de 2014, rol 39-2014.

${ }^{116}$ Véase informe Gonçalves de Castro Mendes (2016), pp. 1013-1045.

${ }^{117}$ Comp. en el "recurso de protección" chileno como proceso de urgencia lo sostenido por BORDALí (2004), pp. 269-288.

${ }^{118}$ Como referencia el Informe de Argentina plantea puntos que son los comunes a partir del fallo Mendoza I por la CSJN: “(i) la noción "derechos de incidencia colectiva”; (ii) la legitimación colectiva de cada uno de los sujetos contemplados en el art. $43 \mathrm{CN}$; (iii) el alcance subjetivo de la cosa juzgada; y (iv) la vía procesal por medio de la cual debían canalizarse este tipo de pretensiones". Berizonce, Bermejo, Sucunza (2015), Informe Argentina. 
de la vulneración de los derechos fundamentales o en aquellos casos en los que hay un interés público comprometido. Hay muchos conceptos abiertos y generales que pueden finalmente ser de utilidad para sustentar la existencia de una cierta flexibilidad procesal ${ }^{119}$. En contraste con ese panorama general está el Derecho brasileño, con un desarrollo doctrinario, jurisprudencial y legislativo pionero y consolidado en el área. El ámbito de los derechos colectivos (sentido amplio) roza siempre con los temores del activismo judicial, con el cual podrá o no coincidirse. Al relacionarse con los aspectos tangibles de la vida cotidiana del ciudadano como consumidor, inserto en un ambiente o en su calidad de usuario de servicios básicos son temas normalmente complejos y muy vinculados a la implementación de políticas públicas, pero, además, tienen relación con necesidades que no pueden postergarse ${ }^{120}$. Por ello un justo equilibrio en las regulaciones modernas de procesos colectivos es incorporar técnicas suplementarias como decisiones vinculantes secundum eventum litis ${ }^{121}$.

Los estándares de lo "sumario" en cualesquiera de sus perspectivas según lo visto para un proceso individual podrían ser inadecuados para uno colectivo. El grado de complejidad y la trascendencia social, tanto económica como política de su discusión y resolución imponen prudencia, pero al mismo tiempo urgencia en dar una respuesta. Así, en la tutela cautelar ambiental los requisitos de verosimilitud y de peligro en la demora podrían ser conceptualmente similares que un proceso individual, debiendo la misión y la visión de lo cautelar adoptar un papel más bien preventivo para la efectividad de la medida (en particular, por la potencialidad del daño y la magnitud de los intereses en juego ${ }^{122}$. Esta circunstancia se agrava aún

${ }^{119}$ Comp. Vitorelli (2016), pp. 200 y 445.

${ }^{120}$ Dondi, Ansanelui, Comoglio (2015), pp. 321-341. Comp. lo decidido como acción constitucional en el Ecuador Corte Constitucional sobre medidas cautelares Corte Constitucional del Ecuador. Sentencia Nº034-2012.

${ }^{121}$ Comp. Marin, Lunelli (2011), pp. 75-88.

${ }^{122}$ En este sentido, la Corte Constitucional colombiana pudo ya manifestarse sobre la necesidad de mecanismos expeditos para la tutela de derechos colectivos incluso mediante cautelares con carácter provisorio. Ello en consideración de la necesaria urgencia de protección de esos derechos, sentencia C-284/14 CC. También se suman en la complejidad de los procesos colectivos las llamadas "sentencias estructurales", es decir, decisiones que buscan aplicar una solución a un caso particular para aplicar derechos sociales y económicos con programación de políticas públicas para ello -un extenso y comparado desarrollo sobre el tema puede verse en BAZAN (2015)- donde la urgencia de la decisión se proyecta para una planificación a mediano plazo. Así, un ejemplo está dado en otra decisión de la corte colombiana en 2004 (sentencia T-25) sobre los desplazados y reconocimiento de derechos personalísimos al desarrollo de sus derechos privados en la sociedad ordenando al Estado que se encargue de aplicar las políticas públicas para su implementación. 
más cuando en los procesos se ven afectados los derechos fundamentales cuya tutela es preferente o versan sobre bienes colectivos ${ }^{123}$.

En Argentina, la propia Corte Suprema reafirmó el carácter híbrido de la regulación sobre la materia existente en ese país, caracterizado por categorías de derechos al estilo brasileño y un proceso más cercano a las acciones de clase de origen estadounidense ${ }^{124}$. La regulación es dispersa, tanto en el ámbito federal como de los Estados provinciales. Ley General del Ambiente $\mathrm{N}^{\circ}$ 25.675, la LDC y el reciente Código Civil y Comercial de la Nación ${ }^{125}$. Son, sin embargo,

"reglas aisladas y parciales, carentes de sistematicidad, las cuales omiten el abordaje de un cúmulo de cuestiones imprescindibles para poder afirmar la validez de cualquier sistema de procedimiento colectivo (v.gr., publicidad y notificación, control de representatividad adecuada, entre otros)" ${ }^{126}$.

Ha sido la propia Corte Suprema la que ha normado reglamentaria y jurisdiccionalmente el proceso colectivo. El caso emblemático es "Halabi"127.

${ }^{123}$ Sobre la creación pretoriana en Argentina, puede verse LOSARdo (2015), pp. 107131. Véase al respecto los fallos de la Corte Suprema de Argentina "Barrick Exploraciones Argentinas S.A. y otro c/ Estado Nacional s/ acción declarativa de inconstitucionalidad" -B. 140 XLVII- res. del 3 de julio de 2012; "Asociación de Esclerosis Múltiple de Salta c/ Ministerio de Salud -Estado Nacional s/ acción de amparo- medida cautelar”, res. del 18 de diciembre de 2003 - Fallos: 326:4931, entre otros. Comp. el excelente aporte de VERBIC, SuCunZa (2016), pp. 809-818.

${ }^{124}$ Berizonce, Bermejo, Sucunza (2015). Informe Argentina.

${ }^{125}$ Ibid.

${ }^{126}$ Ibid.

${ }^{127}$ Corte Suprema de Justicia de la Nación, Halabi, Ernesto c/ PEN -Ley 25.873, Dto. 1563/04 s/ amparo ley 16.986 (24 de febrero de 2009), Fallos 332:111. "El caso 'Halabi' involucraba un planteo de inconstitucionalidad contra una ley formal del Congreso y su Decreto reglamentario, por medio de los cuales se exigía a las empresas de telecomunicaciones el registro de conversaciones privadas y su almacenamiento por diez años a fin de ser observadas remotamente por el Ministerio Público Fiscal. A diferencia del caso 'Mendoza', el conflicto ventilado en 'Halabi' llegó a la CSJN en instancia de apelación extraordinaria e involucraba un número aun mayor de interesados (el grupo afectado por la normativa impugnada comprendía absolutamente todos los usuarios del servicio telefónico)”. Berizonce, Bermejo, Sucunza (2015). Informe Argentina. Comp. lo decidido por los tribunales en Corte Suprema de Justicia de la Nación, "Neira, Luis Manuel y otra c/ Swiss Medical Group S.A.”, Fallos: 326:2906, sentencia del 21 de agosto de 2003; Corte Suprema de Justicia de la Nación, "Pesquera Leal S.A. c/ Estado Nacional - Secretaría de Agricultura, Ganadería y Pesca s/ medida cautelar", sentencia del 19 de octubre de 2000; Corte Suprema de Justicia de la Nación CSN, 30 de septiembre de 2008, "I., C.F. c. Prov. de Buenos Aires". En sentido similar: T. Col. Flia. No 5, Rosario, 7 de noviembre de 2008, La Ley Litoral, 2009, p. 511. 
Se refiere al debido proceso colectivo y con ello a la tutela sumaria como componente de este,

"siendo claramente operativa, así como también es obligación de los jueces darle eficacia, cuando se aporta nítida evidencia sobre la afectación de un derecho fundamental y del acceso a la justicia de su titular" 128 .

En Argentina cabe mencionar la norma en materia de consumidores, la que impone la aplicación del proceso de conocimiento más abreviado, a menos que fundadamente el juez establezca la necesidad de un proceso de conocimiento más adecuado sobre la base de la complejidad de la controversia $^{129}$. "Ésta y su condición de ley especial (tutela diferenciada), son las únicas referencias que podemos extraer asociadas a la idea 'sumaria'"130. Sí se reconoce en materia de los procesos colectivos el marcado activismo judicial y la consolidación del papel protagónico del juez como director del proceso para maximizar el servicio de la justicia ${ }^{131}$. Fuera de ello, no existiendo una regulación de los procesos colectivos, tampoco hay una particular de lo cautelar. Ahora bien, lo cautelar en el ámbito de los procesos colectivos parece tener relevancia cuando es el Estado argentino el demandado. Así, la ley $\mathrm{N}^{\circ} 26.854$ de medidas cautelares contra el Estado, se aplica cuando el proceso colectivo tenga como demandada a la administración pública nacional centralizada o descentralizada ${ }^{132}$.

La regulación de las acciones y de los procesos colectivos en España está dispersa entre la legitimación, la incorporación de los terceros al

${ }^{128}$ Citado por Berizonce, Bermejo, Sucunza (2015). Informe Argentina.

${ }^{129}$ Comp. estos casos de acciones colectivas encausadas mediante el acciones de tutela de derechos fundamentales con medidas cautelares anticipatorias o interinales. Corte Suprema de la Nación (Argentina), 30 de septiembre de 2008, "Comunidad Indígena Eben Ezer c. Prov. de Salta. Ministerio de Empleo y la Producción”, Fallos 331:2119; La Ley, 2008-F, 93; Corte Suprema de la Nación (Argentina), CSN, 8 de abril de 2008, U. 30.XLII, "Unión de Usuarios y Consumidores c. Cia. Euromédica de Salud s/Amparo"; Corte Suprema de la Nación (Argentina), CSN, 25 de marzo de 2003, Fallos, 326:970; La Ley, 2003-E, p. 305.

${ }^{130}$ Berizonce, Bermejo, Sucunza (2015). Informe Argentina.

${ }^{131}$ Ibid.

${ }^{132}$ Berizonce, Bermejo, Sucunza (2015). Informe Argentina: "Entre las críticas más importantes que cabe formular a dicho régimen se destacan: la prohibición de la tutela anticipada, la obligatoriedad-deber del informe previo al dictado de la medida y la incidencia de la vista previa del Ministerio Público, la vigencia temporal de las medidas adoptadas, la prohibición de afectar los recursos y bienes del Estado, de perturbar los cometidos que se realizan con ellos y de imponer sanciones pecuniarias a funcionarios, el alcance limitativo de la contracautela, la ampliación de las prerrogativas procesales del Estado, el efecto suspensivo del recurso de apelación y el trato privilegiado dispensado a ciertos grupos en situación de vulnerabilidad y algunos derechos sensibles y no a otros". 
proceso y la cosa juzgada principalmente. La regulación de los procesos colectivos parece ceñirse al ámbito del consumo. No se emplea en ningún caso la voz 'sumario' 133 . En materia de acciones colectivas, el sistema español diferencia entre las acciones resarcitorias y de cesación/inhibitorias con una regulación especial a partir del Derecho Comunitario (para defensa de los intereses colectivos y difusos de los consumidores y los usuarios), las cuales tienen una tramitación mediante el "juicio verbal". Recuérdese que ello tiene relación con la celeridad, pero no con un conocimiento "sumario" en el sentido de un conocimiento menos profundo y sin la fuerza de cosa juzgada, tal cual como se vio en relación con España ${ }^{134}$.

En República Dominicana, no obstante, el rango constitucional dado a los derechos colectivos y su resguardo por varias leyes especiales, no se ha desarrollado un sistema de tutela de los derechos de incidencia colectiva. El medio para su resguardo es el amparo colectivo como procedimiento constitucional, el que es rápido y sencillo, no logrando ser adecuado para canalizar aquellas acciones de protección de los derechos colectivos e intereses difusos ${ }^{135}$.

En Chile no existe un sistema unificado que regule los procesos colectivos. Recién desde 2004 con la reforma a la ley $\mathrm{N}^{\mathrm{O}} 19.496$ sobre protección de los derechos de los consumidores, se introdujeron los procesos 164 colectivos en ese tópico, teniendo presente que en esta materia las acciones de clase o colectivas son de conocimiento de los tribunales ordinarios de justicia $^{136}$ y no a la justicia denominada de policía local ${ }^{137}$.

${ }^{133}$ Sostienen Gascón Inchausti, García-Casas (2015): "El sistema vigente para la tutela colectiva de los derechos no es satisfactorio y sus deficiencias se están poniendo de manifiesto con claridad en los últimos tiempos, debido a la proliferación de demandas colectivas asociadas a la comercialización de productos financieros abusivos o engañosos. Sin embargo, no hay propuestas de reforma concretas y, en todo caso, la sumariedad -en sentido técnico- no se halla en la agenda de las propuestas de reforma"; Armenta Deu, Oromí Vall-llovera, Pereira Puigvert (2015). Informe España: "Formalmente no ha sido presentado ningún Anteproyecto. Como miembro de la Comisión General de Codificación del Ministerio de Justicia”.

${ }^{134}$ Gascón Inchausti, García-Casas (2015).

${ }^{135}$ Cruceta (2015). Informe República Dominicana.

${ }^{136}$ Importante resultó en Chile simplificar el examen de admisibilidad de la demanda sobre la base de la ley $\mathrm{N}^{\mathrm{o}} 19.496$ para la tutela de del interés colectivo o difuso de los consumidores permitió una mayor celeridad sin menoscabar el control de seriedad y verosimilitud de la demanda. Ello puede acompañarse de tutelas más urgentes como las cautelares cuando lo requiera. Véase así lo decidido en este sentido por la Corte Suprema del 28 de octubre de 2016, rol 111-2016.

${ }^{137}$ Véase completo informe sobre el tema Aguirrézabal Grünstein (2014), passim; igualmente complementar con Aguirrézabal Grünstein, Meneses Pacheco (2013), pp. 391-422; un estudio más contemporáneo puede verse en Meneses Pacheco (2017), pp. 320-410. 
En otras leyes especiales relacionadas con los intereses difusos, colectivos, de grupo o públicos se regulan las acciones y los procesos con aspectos propios o, bien, de las acciones populares ${ }^{138}$. En ninguno de los casos se hace referencia a la tramitación sumaria ${ }^{139}$. Sí debe mencionarse el proceso previsto dentro de la nueva institucionalidad ambiental que incorpora una regulación de medidas cautelares innovativas en proceso en una área de intereses difusos y colectivos clara ${ }^{140}$.

Perú tampoco tiene una regulación de los procesos colectivos, lo que nada obsta a que pueda aplicarse la tramitación sumarísima, al no haber disposición en contra. En el caso de los procesos colectivos en defensa de los derechos del consumidor, estos se caracterizan por su tramitación sumarísima. Ahora bien, ya que puede acumularse a esta acción una indemnizatoria, conlleva a que materialmente serían competentes unos juzgados que excediendo determinada cuantía no podrían conocer sobre aquello; o que debiendo dar tramite a una demanda colectiva con una cuantía mayor a las admisibles para este procedimiento, deba tutelarse tal demanda en la vía abreviada. No hay así un proceso especial y rápido para determinados derechos colectivos, salvo mediante la vía del amparo de derechos fundamentales, que sí tiene una tramitación sumaria ${ }^{141}$.

${ }^{138}$ Así, en los procesos colectivos en materia medioambiental (2004) y en las "acciones populares contenidas en otras leyes especiales, como el art. 12 del DL No 3557, que establece disposiciones sobre protección agrícola, art. 149 y sgtes. de la Ley General de Urbanismo y Construcciones, art. 42 de la Ley $N^{\circ} 17.288$ sobre Monumentos Nacionales, art. 5 de la Ley 18.378, sobre Protección de la Agricultura, art. 30 de la Ley No 18.362 de Áreas silvestres protegidas por el Estado, art. 161 del Código Sanitario". LETELIER, TAVOLARI, VALENZUELA (2015). Informe Chile.

${ }^{139}$ Existe un proyecto de ley que modifica la ley de protección de los derechos de los consumidores $\mathrm{N}^{\circ} 19.496$ incorporando una tramitación breve y sumaria ante la justicia de policía local. Véase Letelier, Tavolari, Valenzuela (2015). Informe Chile.

140 Aguirrézabal Grünstein (2016), pp. 23-49; véase igualmente Pérez Ragone (2016), pp. 213-234. Véase sobre la tutela cautelar en la institucionalidad ambiental lo decidido por Segundo Tribunal Ambiental de Santiago. Medida cautelar de oficio en contra de Servicios Generales Larenas Ltda. 26 de septiembre de 2013. Causa rol D-62013. También un fallo de la Corte Suprema sobre el daño ambiental reparable alude a considerar nuevos mecanismos procesales (Corte Suprema de Justicia, 10 de diciembre de 2015, rol 25720-2014). El detalle de la incorporación expresa de la cautelar "innovativa" en el área demuestra la importancia de adecuar mecanismo cautelares en procesos colectivos como se lo hace en el ambiental. Así, Segundo Tribunal Ambiental de Santiago. Medida cautelar 26 de septiembre de 2013. Causa rol D-6-2013. Y en contraste el rechazo por de una innovativa el Tercer Tribunal Ambiental de Valdivia, exigiendo mayores antecedentes para poder ordenar esa medida (detalle del perjuicio irreparable) rol D-15-2016.

${ }^{141}$ Priori Posada, Delgado Suárez (2016). Informe Perú. Por cierto, la comparación con el ejercicio de acciones constitucionales ante el Tribunal Constitucional se logran beneficios para los derechos de personas con incapacidad; véase Tribunal Constitucional del Perú, 2437-13-AA. 
En Bolivia se regula la "acción popular" en el Código Procesal Constitucional para garantizar los derechos e intereses colectivos mediante un procedimiento rápido, aplicándose las reglas propias del procedimiento extraordinario existente en materia civil ${ }^{142}$. Se debe mencionar que está el proyecto sobre Jurisdicción Agroambiental, que contiene una regulación específica para los procesos colectivos, adoptando normas similares al Código Modelo de Procesos Colectivos para Iberoamérica ${ }^{143}$.

El Derecho brasileño tiene una pluralidad de leyes que regulan los procesos colectivos, un verdadero "sistema de proceso colectivo". A partir del Código de Protección del Consumidor, que describe las características de los derechos e intereses que tutela, se admiten todo tipo de acciones para su adecuada y efectiva protección ${ }^{144}$. En otras palabras, la acción colectiva brasileña no tiene un proceso específico. Solo se regulan algunos institutos específicos como la legitimación, la regulación de la competencia o la cosa juzgada. Puede emplearse la tramitación establecida en el $C P C$, establecida para las demandas individuales. Así, puede decirse que la legislación brasileña sí concibe un procedimiento sumario colectivo para tutelar los derechos e intereses descritos en la normativa de consumidores. Existen, además, algunos procedimientos específicos para ciertas controversias colectivas en materia administrativa y laboral. Un procedimiento especial regula una acción contra los actos ilegales de la administración pública, cuya principal característica es su carácter sumario, pues suprime la fase de prueba y simplifica sustancialmente el procedimiento ${ }^{145}$. A ello hay que agregar que en el nuevo $C P C$ de 2015 contempla la admisibilidad de los contratos procesales, aunque es objetable su aplicación para los procesos colectivos, justamente fundándose en el carácter disponible de los derechos litigiosos o, bien, por las dificultades operativas en ello ${ }^{146}$. Esto resulta hasta ahora controvertido. Así, por ejemplo, hay una pluralidad de legitimados activos concurrentes, siendo varios de ellos funcionarios públicos. Si uno de ellos decidiera hacer valer una acción y luego acordar un determinado procedimiento, se podrían suscitar conflictos con el derecho a ser oído de los otros legitimados activos ${ }^{147}$. El proceso colectivo también hace uso de los amplios mecanismos de tutela cautelar ya descri-

${ }^{142}$ Comp. lo fallado en estos casos por el Tribunal Constitucional peruano Tribunal Constitucional del Perú. Expte. No 0025-2005-PI/TC y 0026-2005-PI/TC, 25 de abril de 2006, párr. 26; Tribunal Constitucional del Perú. Exp. N. ${ }^{\circ}$ 2945-2003-AA/TC. 20 de abril de 2004. párr. 30

${ }^{143}$ Villarroel Bustios, Mostajo Barrios (2015). Informe Bolivia.

${ }^{144}$ Cruz Arenhart, Osna (2015). Informe Brasil.

${ }^{145}$ Ibid.

${ }^{146}$ Ibid.

${ }^{147}$ Ibid. 
tos, aunque se debe tener presente que existe, además, una prohibición de carácter legal de otorgar tutelas cautelares colectivas e individuales de urgencia en determinadas áreas del Derecho Público, disposición que ha sido cuestionada en relación con su constitucionalidad ${ }^{148}$. En definitiva, aunque se permite el uso de cualquier procedimiento para la tutela de los derechos e intereses colectivos, ello queda desvirtuado en la práctica, aplicándose por defecto el proceso ordinario, ya que la propia naturaleza de las controversias colectivas obsta a la aplicación de una alternativa sumaria. Lo anterior contrasta con la existencia de estatutos especiales para una adecuada protección de los ancianos, los niños y otras personas que atendida su condición se consideran vulnerables, imponiéndose la aplicación de un proceso rápido ${ }^{149}$.

En el Derecho uruguayo hay una regulación en materia de procesos colectivos referida a la legitimación, los efectos de la sentencia y la cosa juzgada. Se aplica indistintamente si se trata de un interés colectivo o difuso. El CGP confiere legitimación al Ministerio Público o a cualquier interesado. También reconoce esa calidad a las instituciones o asociaciones de interés social "que según la ley o a juicio del tribunal garanticen una adecuada defensa del interés comprometido" ${ }^{150}$. En otra sección, contempla los "Efectos de la cosa juzgada en los procesos promovidos en representación de intereses difusos", estableciendo que la sentencia dictada en estos procesos
"tendrá eficacia general, salvo si fuera absolutoria por ausencia de pruebas, en cuyo caso, otro legitimado podrá volver a plantear la cuestión en otro proceso".

Sobre la base de esta disposición, se sostiene que correspondería acudir a la vía del proceso contencioso ordinario (art. 348 del CGP). Solo excepcionalmente se debería admitir el proceso de amparo, si se dan en el caso concreto sus estrictos presupuestos subjetivos y objetivos de procedencia (ley $\mathrm{N}^{\mathrm{O}}$ 16.011, de 19 de diciembre de 1988). Las dos vías admiten la adopción de medidas cautelares o provisionales. Estas medidas pueden adoptarse a pedido de parte y, en el caso del proceso de amparo, aun de oficio (arts. 311 y 317 del $C G P$ y art. $7^{\circ}$ de la ley $\left.\mathrm{N}^{\mathrm{o}} 16.011\right){ }^{151}$. Inicialmente

${ }^{148}$ Solo recordar acá en este ámbito, decisiones de los tribunales superiores de Brasil ordenando el acceso al derecho de salud como la provisión de medicamentos en el año 2009 en decisión STA-AgR n. 175. Comp. Cruz Arenhart, Osna (2015). Informe Brasil.

${ }^{149}$ Cruz Arenhart, Osna (2015). Informe Brasil.

${ }^{150}$ Valentin, Hegedus (2015). Informe del Uruguay.

${ }^{151}$ Comp. Landoni Sosa, Pereira Campos (2002), pp. 74 y 77; Pereira Campos (2016), pp. 1255-1261. 
se discutió acerca de la procedencia del amparo en estos casos, pero en la actualidad la doctrina lo admite unánimemente, aunque como esta señala

"nuestra jurisprudencia ha desestimado tal posibilidad en la mayor parte de los casos, invocando que el objeto propuesto en dichos procesos supera la sumarísima estructura procesal del amparo y/o que no se verifican algunos otros de sus rigurosos presupuestos"152.

No existe un proceso sumario específicos para estos intereses, como ya indicamos. Sin duda, resulta imprescindible avanzar hacia una regulación más completa y sistemática de los intereses genéricamente llamados colectivos, que incluya soluciones estructurales adecuadas para su efectiva tutela.

Como puede apreciarse, los temas involucrados en los procesos colectivos tienen dos componentes que los hacen en especial sensibles: la sumariedad en su conocimiento, la complejidad y la urgencia social de la decisión. Cualquier enfatización en uno u otro lado debe ser ponderada, ya que los estándares válidos para una controversia individual no suelen ser adecuados para una colectiva.

Lo sumario en cuanto al nivel de cognición exigido tiene una profunda relación con la "tutela, las medidas, los procesos o los procedimientos cautelares". El uso del término 'cautelar' varía en extensión no tanto en comprensión.

i) Para una visión lo "cautelar" se hace valer para tutelar un proceso que reviste la calidad de principal, tiene más características estáticas, pues se concentra solo en lo estructural. Ello se condice con acentuar el carácter "provisorio" y la "instrumentalidad" como características principales. Los requisitos suelen referir al peligro en la demora y a la verosimilitud del Derecho y tienen en vista su resguardo por la demora natural del proceso principal ${ }^{153}$.

ii) Para otra posición debe asumirse una visión más dinámica de lo cautelar, que tendría como objetivo hacer más eficaz la actividad de la Justicia. Frente al fenómeno de la urgencia y como un equilibrio contra el tiempo que pueda insumir el pronunciamiento de una sentencia, debiera admitirse la posibilidad de la satisfacción provisoria de los derechos que no admiten dilación ${ }^{154}$.

${ }^{152}$ Valentin, Hegedus (2015). Informe del Uruguay.

${ }^{153}$ En detalle véase esta visión en Montesano (1999), p. 309.

${ }^{154}$ Comp. Calamandrei (1936), p. 21. 
iii) Finalmente, una visión más desenvuelta en determinados países de Iberoamérica repiensan lo "cautelar", tanto en lo estructural como en lo dinámico a partir de la adecuada tutela de los derechos. Son mucho más abiertas que las señaladas en (ii) y con nuevos paradigmas que propenden la superación de inconsistencias y varias contradicciones. Incluso, coadyuvan a un mejor diálogo con el proceso civil comparado ajeno al mundo iberoamericano ${ }^{155}$.

Veamos algunos ejemplos del modelo (i). En Venezuela este tipo de medidas se denominan "providencias preventivas" y comprenden el secuestro, la retención, la prohibición de enajenar y el arraigo o la prohibición de ausentarse ${ }^{156}$. El proceso civil cubano, por su parte, se limitó a la regulación del embargo como una única medida, pensando en garantizar las responsabilidades pecuniarias relacionadas con la acción que se ejerce o que se pretende ejercer ${ }^{157}$. Por ello es posible sostener que el sistema desconoció la tutela cautelar. Recién con el decreto ley N ${ }^{\circ} 241$ (2006) referido a aquellas contiendas de carácter económico se hizo extensivo al proceso de familia y civil, que creó un régimen cautelar que resulta insuficiente, ya que

"no logró un dibujo adecuado de los presupuestos en tanto concierta, cómo único con ese carácter, el que reside en la existencia del peligro, pues sitúa el fumus solo para las reclamaciones de pago y la caución como potestativo del tribunal”.

Según lo regulado, la medida se concede en tanto existan "circunstancias que evidencien el riesgo cierto de daño irreparable para la parte actora", sin especificar si se trata de un riesgo presente o futuro ${ }^{158}$. En Chile, el Código de Procedimiento Civil regula las cautelares bajo la designación de "precautorias", las que son aplicables accesoriamente a cualquier tipo de procedimiento (el término 'cautelar' se emplea en la nueva justicia laboral, de familia y penal). Las "precautorias" requieren la acreditación del peligro en la demora y la verosimilitud en el Derecho ${ }^{159}$ con un nivel no elevado de exigencia probatoria y con previa notificación a la contraparte en situaciones excepcionales. La existencia de medidas típicas o nominadas se complementa con la posibilidad de precautorias innominadas o atípicas.

${ }^{155}$ Véase MARINONi (2013), pp. 1353-1367.

${ }^{156}$ Falconi Puig (2015). Informe Ecuador.

${ }^{157}$ Mendoza Díaz (2015) Informe Cuba.

${ }^{158}$ Ibid.

${ }^{159}$ Letelier, Tavolari, Valenzuela (2015). Informe Chile. 
Como ejemplo del modelo (ii) se puede mencionar el caso de Argentina, donde una medida cautelar se relaciona con

“el proceso principal ya iniciado o que se habrá de iniciar, a cuyo efecto el régimen legal prevé un plazo de caducidad de no promoverse el juicio al que accede la cautelar. Los requisitos son la verosimilitud del derecho, el peligro en la demora y la contracautela"160.

No tienen un fin en sí mismas, sino que están preordenadas a una futura decisión definitiva, tienen el carácter de urgentes y son provisorias. Desbordando la estructura de la "tutela cautelar" se incluyen, además, entre los procesos urgentes a las llamadas medidas anticipatorias y a las autosatisfactivas: con notas de mayor celeridad, "sumariedad" y postergación de la bilateralidad. Las "autosatisfactivas" importan una satisfacción definitiva de lo requerido y, por ende, son autónomas y no dependen de un proceso principal (no tienen el carácter de instrumental ni provisional) ${ }^{161}$. El nivel del estándar para conceder una medida autosatisfactiva es mayor al requerido para una cautelar ${ }^{162}$.

Otro ejemplo a mencionar es España, donde las medidas cautelares se ordenan a petición de parte y con un contenido que puede ser diseñado y propuesto por el requirente de acuerdo con la demora en ese caso particular. La medida solicitada debe reunir dos requisitos:

a) la medida tiene que ser exclusivamente conducente para una tutela judicial que otorgará una eventual sentencia favorable, cuya efectividad no puede ser afectada durante el proceso (se impide así el uso de la medida para presionar a la contraparte);

b) la medida tiene que ser proporcional (no sustituible por otra menos gravosa). La propia regulación española enuncia las medidas que

${ }^{160}$ Berizonce, Bermejo, Sucunza (2015). Informe Argentina.

${ }^{161}$ Ibid.: "existen legislaciones provinciales que expresamente la receptaron, por ejemplo, las Provincias de Chaco, Formosa, La Pampa, Corrientes, Santiago del Estero y San Juan. Empero, su falta de previsión no es un obstáculo para su dictado".

${ }_{162}$ Ibid: "De la comparación de los distintos sistemas, entre los que existen básicamente coincidencias, se puede mencionar lo siguiente: 1) Se las distingue de las medidas cautelares, si bien en todas las reglamentaciones se prevé la posibilidad de requerir una contracautela; 2) En todos los sistemas se regula la posibilidad de un traslado o sustanciación previa a su distado, en cambio, en San Juan se establece como obligatorio. 3) En cuanto a la prueba, al momento de solicitarla se deben acompañar todos los elementos probatorios que fundamenten la petición. 4) Todos los sistemas regulados prevén un límite temporal a la medida autosatisfactiva. 5) Todos prevén una oposición o impugnación por el afectado, si bien se difiere en la vía: en Chaco, Formosa, Corrientes y San Juan se regula la apelación o el inicio de un juicio declarativo general; en La Pampa se agrega, además de esas opciones, que pueda pedir la suspensión de la medida o articule revocatoria; en Santiago del Estero, sólo se dispone la apelación”. 
serían ejemplos de cautelares, es decir, es una regulación abierta a la creación de las partes y del tribunal ${ }^{163}$.

También es posible que se otorguen medidas cautelares como órdenes y prohibiciones de contenido similar a lo que se espera sea el contenido de la sentencia estimatoria futura. Son las cautelares anticipatorias con una eficacia provisional supeditada al tiempo de duración del proceso de conocimiento. Solo pueden otorgarse determinadas medidas como anticipatorias. Los presupuestos para el otorgamiento de las cautelares anticipatorias son el peligro en la demora, una apariencia favorable a la pretensión del demandante y una caución o fianza. Pueden solicitarse con o sin la audiencia de la contraparte ${ }^{164}$.

En Bolivia, el proceso cautelar se regula como accesorio a un proceso principal. Requiere que se acredite la verosimilitud del derecho y el peligro de perjuicio mediante prueba documental sin necesidad de "prueba plena" y sin contracautela (con excepción de la intervención judicial) ${ }^{165}$.

En Portugal, las cautelares tienen por finalidad evitar el peligro en la demora entendido como la lesión o la continuación de la lesión de un derecho a causa de la dilación en ser reconocido o tutelado judicialmente $\left(\operatorname{art} .365 .^{\circ}, \mathrm{N}^{\mathrm{o}} 1\right.$, e $368 .^{\circ}, \mathrm{N}^{\mathrm{o}} 1$ ). Es requisito la "prueba sumaria" o la mera justificación del derecho amenazado y basta la sola verosimilitud o plausibilidad de la existencia del derecho que se alega para el otorgamiento de la medida. Pueden ser nominadas o innominadas y decididas con o sin audiencia de la contraparte, según sea ello adecuado o no con el fin de la medida ${ }^{166}$.

Incluibles en el modelo (iii) pueden mencionarse los casos de Uruguay y Brasil. El CGPde Uruguay contempla una "potestad cautelar genérica". El art. 316.1 establece que el tribunal "podrá disponer las medidas que estime indispensables, siempre que sean idóneas para el cumplimiento de la finalidad cautelar". Las medidas deben ser idóneas, adecuadas, y procedentes, razones que justifican que sean precisas en su alcance, en los fundamentos de hecho y en la determinación de contracautela. En la demanda se deben alegar y acreditar los requisitos exigidos por el numeral 2 del art. 312: "la existencia del derecho y el peligro de frustración deberán probarse sumariamente" 167 . Es importante destacar que expresamente se refiere a que la medida debe ser adecuada para evitar que se cause a la parte, antes de la sentencia, una lesión grave o de difícil reparación o,

\footnotetext{
${ }^{163}$ Gascón Inchausti, García-Casas (2015). Informe España.

${ }^{164}$ Ibid.

165 Villarroel Bustios, Mostajo Barrios (2015). Informe Bolivia.

${ }^{166}$ Lebre de Freitas, Teixeira de Sousa, Soares Pereira (2015). Informe Portugal.

${ }^{167}$ Valentin, Hegedus (2015). Informe del Uruguay.
} 
bien, para asegurar provisionalmente la decisión sobre el fondo ${ }^{168}$. El CGP contempla, también, la posibilidad de ordenar medidas anticipadas provisionales ${ }^{169}$. Las que requieren de un tratamiento diferenciado porque sus caracteres exorbitan el ámbito de las medidas cautelares típicas ${ }^{170}$. Así, en el año 2013 se introdujo una reforma que estableció la tramitación bilateral previa para poder ordenar estas medidas. Se sostiene en el informe que:

"Actualmente estamos asistiendo a una extensión expansiva de lo cautelar: el proceso de amparo, la ejecución provisional de la sentencia, las medidas provisionales y anticipadas y las autosatisfactivas, todas ellas participan de lo cautelar" ${ }^{\prime 17}$.

Todas estas alternativas participan del carácter de la provisionalidad y con ello de la temporalidad. La doctrina reconoce la existencia de otras medidas urgentes que por sí son "autosatisfactivas" y, por ende, con características de definitividad en sus efectos. Si bien no hay regulación en el $C G P$ es posible encontrar supuestos en leyes especiales como la Ley de Sociedades Comerciales y en la Ley de Violencia Doméstica ${ }^{172}$.

El sistema procesal civil brasileño ha sido prolífico, tanto en el siglo $\mathrm{xx}, \mathrm{y}$, en especial, en el xxI en el desarrollo de herramientas relaciona172 das con lo cautelar, ya con disposiciones expresas en el Código Buzaid de 1973. En el Código de 2015 se introducen reformas que de alguna manera responden al desarrollo dogmático y jurisprudencial extraordinario previo sobre el tema ${ }^{173}$. Así, emplea el género de "tutela provisional", que comprende supuestos tanto satisfactivos como no (cautelares). En ambos casos (tutelas satisfactivas y cautelares) pueden solicitarse antes o como incidente en relación con un proceso principal (con o sin audiencia previa a la parte contraria). La tutela provisional cautelar se funda en la urgen-

${ }^{168}$ Valentin, Hegedus (2015). Informe del Uruguay.

169 Ibid.: "Ese tipo de decisiones ya no reciben el nombre tradicional de medidas cautelares y aparecen denominaciones como medidas provisionales, anticipadas, de seguridad, precautorias, autosatisfactivas, etc.”.

${ }^{170}$ Ibid.: El art. 317 del CGP enuncia que el tribunal puede "anticipar la realización de determinadas diligencias, para evitar que se cause a la parte, antes de la sentencia, una lesión grave o de difícil reparación o para asegurar provisionalmente la decisión sobre el fondo. Las medidas anticipadas, lo que buscan es tratar de adelantar, temporalmente, la resolución de una pretensión. De acuerdo a esta definición resulta natural que toda medida provisional será anticipada, pero no se dará siempre la inversa. Es decir, no toda medida anticipada participa de lo provisional. Ya que ese anticipo puede devenir en definitivo".

\footnotetext{
${ }^{171}$ Ibid.

172 Ibid.

${ }^{173}$ Cruz Arenhart, Osna (2015). Informe Brasil.
} 
$\mathrm{cia}^{174}$, mientras que la satisfactiva puede justificarse tanto en la urgencia como en la evidencia del derecho que se hace valer ${ }^{175}$.

\section{CONCLUSIONES}

La gestión y la distribución del tiempo mientras se examina como hacer justicia forma parte de lo "justo". La gestión del tiempo y su adecuada distribución entre las partes y el juez permite una mejor planificación y previsibilidad. La justicia civil "acelerada" en cualesquiera de las manifestaciones que se vio en relación con lo sumario como procedimiento simplificado o nivel de conocimiento judicial aminorado tienen su lugar ganado en la tutela adecuada de los derechos ${ }^{176}$. En materia de justicia penal, la mayoría de los ordenamientos contemplan las alternativas procesales simplificadas, además de un espacio para que ciertos intervinientes, dadas determinadas circunstancias puedan acordar una tramitación con mayor simplificación ${ }^{177}$. La juridicidad va de la mano de la tempestividad

${ }^{174}$ Cruz Arenhart, Osna (2015). Informe Brasil: "Art. 300. A tutela de urgência será concedida quando houver elementos que evidenciem a probabilidade do direito e o perigo de dano ou o risco ao resultado útil do proceso". § 1o Para a concessão da tutela de urgência, o juiz pode, conforme o caso, exigir caução real ou fidejussória idônea para ressarcir os danos que a outra parte possa vir a sofrer, podendo a caução ser dispensada se a parte economicamente hipossuficiente não puder oferecê-la. § 2o A tutela de urgência pode ser concedida liminarmente ou após justificação prévia. § 3o A tutela de urgência de natureza antecipada não será concedida quando houver perigo de irreversibilidade dos efeitos da decisão".

175 Ibid.: "Art. 311. A tutela da evidência será concedida, independentemente da demonstração de perigo de dano ou de risco ao resultado útil do processo, quando: I - ficar caracterizado o abuso do direito de defesa ou o manifesto propósito protelatório da parte; II - as alegações de fato puderem ser comprovadas apenas documentalmente e houver tese firmada em julgamento de casos repetitivos ou em súmula vinculante; III - se tratar de pedido reipersecutório fundado em prova documental adequada do contrato de depósito, caso em que será decretada a ordem de entrega do objeto custodiado, sob cominação de multa; IV - a petição inicial for instruída com prova documental suficiente dos fatos constitutivos do direito do autor, a que o réu não oponha prova capaz de gerar dúvida razoável. Parágrafo único. Nas hipóteses dos incisos II e III, o juiz poderá decidir liminarmente”.

${ }^{176}$ Conviene cerrar con la adhesión a los múltiples fines para los cuales está predispuesto el proceso (más amplio la justicia) civil. Sin responder a ello primero resulta complejo trabajar con nuevos paradigmas. Así sostiene Uzelac: "Civil justice should serve the interests of the society of the twenty-first century, and the new social context imposes the need for significant changes. These changes require clear starting points. Without clearly stated goals, it is hard to make solid and consistent plans, produce indicators of their success and maintain the momentum of the reforms". UzELAC (2014), p. 28.

177 Sin adentrarse en lo penal es interesante resaltar a lo menos dos aspectos en contraste a lo visto hasta ahora: por un lado, la mayoría de los ordenamientos contemplan 
y esa convivencia como equilibrio parece ser curiosamente mucho más compleja en materia civil que en el ámbito penal o, incluso, avances en tutela cautelar como la innovativa en materia ambiental o cautelares mucho más efectivas en tutela de derechos colectivos.

En la justicia civil es necesario superar el falso dilema entre eficacia "o" seguridad. El contraste con los avances en la justicia penal lo demuestran siendo diferentes los intereses en resguardo y casi por un argumento $a$ fortiori imponen rever los paradigmas en el proceso civil. Ambos componentes integran un derecho fundamental procesal, que es el justo proceso, por un lado ${ }^{178}$. Por el otro, hay otros componentes que se suman a ellos, excediendo, por consiguiente, el planteamiento del dilema inicial: el acceso, la eficacia, la eficiencia, la seguridad y otros criterios que deben ser observados. El criterio y el examen de la proporcionalidad imponen una nueva visión, pues no hay una única forma de impartir justicia con seguridad, eficacia y eficiencia ${ }^{179}$.

La transformación del modelo único del proceso ordinario para adaptarlo a los distintos tipos de controversias tiene una especial relación con el principio de proporcionalidad en la distribución de los escasos recursos de la administración de justicia.

La diversificación de la tutela procesal trasunta en la adaptabilidad, 174 la plasticidad o la adecuación de un proceso único a las características singulares de la controversia que a él se somete. Viendo las distintas aplicaciones que tiene, es posible a lo menos inferir una preocupación común por diversificar el procedimiento y adecuarlo a la urgencia o evidencia

la existencia de alternativas procesales simplificadas, además de un espacio para que ciertos intervinientes, dadas determinadas circunstancias puedan acordar una tramitación más expedita. Variables como la importancia del delito, la aplicación del principio de oportunidad por parte del Ministerio Público o la realización de ciertos actos de colaboración por parte del imputado son los presupuestos que han de verificarse para que ello sea posible (Armenta Deu, Oromí Vall-llovera, Pereira Puigvert (2015). Informe España y Gascón Inchausti, García-CASAs (2015). Informe España) De esta forma se concretiza la duración razonable de un proceso penal acorde con las circunstancias que se verifiquen lo que es resaltado en todos los informes nacionales (Villarroel Bustios, Mostajo Barrios (2015). Informe Bolivia; Garderes, Valentin (2007), pp. 128-130 y Valentin, Hegedus (2015). Informe del Uruguay; Cruceta (2015). Informe República Dominicana; Rivera y colaboradores; Ochoa, Martinez, Paz, Camero, Martinez. Informe Venezuela; Falconi Puig (2015). Informe Ecuador; Mendoza Díaz (2015). Informe Cuba; Cruz Arenhart, Osna (2015). Informe Brasil; Letelier, Tavolari, Valenzuela (2015). Informe Chile, también Horvitz, López (2004), tomo II, pp. 482-483 y Maturana, Montero (2010), tomo it, pp. 1088-1090; Maturana, Montero (2010), tomo il, pp. 10881090; Lebre de Freitas, Teixeira de Sousa, Soares Pereira (2015). Informe Portugal.

${ }^{178}$ Comoglio (2008), pp. 1513-1516; para este razonamiento centrado en la justicia civil como eje y refiriendo a la penal véase Oteiza (2015), p. 55 y ss.

${ }^{179}$ Así Settem (2016), pp. 145-147; Comp. Koller (2014), p. 49. 
de la tutela requerida: sea mediante una decisión provisoria sin niveles de exhaustividad, sea mediante vías alternas a una tramitación modelo y general. El cómo acceder a esos mecanismos varía según se admitan papeles al juez y a las partes en esa decisión. Es conveniente avanzar en la diversidad y la flexibilidad procesal para adecuarla a la controversia a decidirse. Adecuarla no solo por la legalidad sino que confiando en el papel conductor del juez y por qué no en el acuerdo y colaboración de las partes.

\section{Bibliografía CITADA}

Aguirrézabal Grünstein, Maite (2014). Defensa de los consumidores y acceso a la justicia. Un análisis del procedimiento colectivo en la legislación chilena. Santiago: Thoomson Reuter.

Aguirrézabal Grünstein, Maite, Claudio Meneses Pacheco (2013). "Los procesos colectivos en Chile: la tutela de los intereses supraindividuales (difusos y colectivos) en el ordenamiento chileno", en Álvaro Pérez Ragone, Pía Tavolari. Derecho Procesal Civil Comparado. Santiago: Thomson Reuters.

Aguirrézabal Grünstein, Maite (2016). "Las medidas cautelares innovativas en la nueva institucionalidad mediambiental". Revista de Derecho Universidad Católica del Norte. Año 23, $\mathrm{N}^{\circ} 1$. Antofagasta.

Amrani-Mekкi, Soraya (2010). "Analyse économique et temps du procès", in Dany Cohen (dir.). Droit et économie du procès civil. Paris: LGDJ.

Andrews, Neil (2009). "Accelerated Justice: Prospective, Interim and Summary Procedures in English Law", in Rolf Stürner, Masanori KawANo (coords.) Current Topics of International Litigation. Tübingen: Mohr Siebeck.

Armenta Deu, Teresa, Susanna Oromí Vall-llovera, Silvia Pereira Puigvert (2015). Informe España. Inédito.

Basilico, Giorgetta (2010). Il procedimento sommario di cognizione, Giusto processo civile. Milano: Treccani.

BAZAN, Víctor (2015). Justicia constitucional y Derechos fundamentales $N^{0} 5$ - La protección de derechos sociales, las sentencias estructurales, Bogotá/Berlín: Konrad-Adenauer.

BAYER, Hieronymus (1853). Theorie der summarischen Processe, München: Literarische-Artistische Anstalt.

Berizonce, Roberto, Patricia Bermejo, Matías Sucunza (2015). Informe Argentina. Inédito.

Biond, Biondo (1921). 'Summatim cognocere“, Bullettino dell'stituto di Diritto Romano, $\mathrm{N}^{\mathrm{o}}$ 30. Milano.

Bordalí, Andrés (2004). "El recurso de protección como proceso de urgencia". Revista Chilena de Derecho. Vol. 31. No 2. Santiago.

Briegleb, Hans Karl (1859). Einleitung in die Theorie der summarischen Processe. Leipzig: Tauchitz. 
Burbank, Stephen (2011). "Problemi di complessita nella attuale pratica civilistica statunitense", in Angelo Dondi (ed.). Elementi per una definizione di complessità processuale. Milano: Guiffrè Editore.

CADIET, Loïc (2007). Les conflits de légalité procédurale dans le procès civil. Paris: Mélanges Boré.

CAdiet, Loïc (2008). "Case management judiciaire et déformalisation de la procédure”. Revue française d'administration publique. Vol. 1. No 125. Paris.

CADiet, Loïc (2012). "Los acuerdos processales em derecho francês: situación actual de la contractualización de processo y de la justicia en Francia”. Civil Procedure Review. Vol. 3. München.

CADIET, Loïc (2016). "L'equilibre entre la rigidité et la flexibilité dans le proces" in Paulo Lucon, Ricardo Aprigliano. Processo em Jornadas. Salvador: Editora Jus Podivm.

Calamandrei, Piero (1936). Introduzione allo Studio Sistematico dei Provvedimenti Cautelari. Milano: CEDAM.

CAPONI, Remo (2008). "Autonomia privata e processo civile: gli accordi processuali". Rivista Trimestrale di Diritto e Procedura Civile, Vol. 3. Milano.

CAPONI, Remo (2016). "Rigidità e flessibilità del processo civile", en Paulo LuCon, Ricardo Aprigliano. Processo em Jornadas. Salvador: Editora Jus Podivm.

Cappelletti, Mauro, Bryant Garth (1978). "Access to Justice: Newest Wave in 176 the Worldwide Movement to Make Rights Effective”. Buffalo Law Review. Vol. 27. New York.

CARPI, Federico (2013). "La specializzazione del giuidice come fattores di efficienza della giustizia civile". Rivista Trimestrale di Dirito e Procedura Civile. Vol. LXVII. $\mathrm{N}^{\mathrm{o}}$ 3. Milano.

CARPI, Federico (1985). "Urgent Relief in Italian Civil Procedure". Israel Law Revierw. Vol. xx. Cambrigde.

CARratta, Antonio (2012a). La tutela sommaria in Europa. Napoli: Jovene Editore.

CARratta, Antonio (2012b). La "semplificaziones" dei riti e le nuove modifiche del processo civile. Torino: G. Gasppichetti Editore.

Carratta, Antonio , Michele Taruffo (2015). Poteri del giudice. Libro Primo art. 112-120. Bologna: Zanichelli Editore.

Chiovenda, Giuseppe (1923). Principii di diritto processuale civile. Napoli: Jovene.

Chizzini, Augusto (2015). "Konventionalprozess e poteri delle parti”. Rivista di Diritto Processuale. Vol. LXx. Padova.

Comoglio, Luigi Paolo (2008). "Tutela differenciata e pari effetività nella giustizia civile”. Rivista di Diritto Processuale. Vol. LXIII. Padova.

CRuceta, José Alberto (2015). Informe República Dominicana. Inédito.

Cruz Arenhart, Sergio, Gustavo Osna (2015). Informe Brasil. Inédito.

Davis, Kerin, Hershkoff, Hellen (2011). "Contracting for procedure". William \& Mary Law Review. Vol. 63. N 2. Virginia. 
Da Rós Bodart, Bruno (2015). Tutela de Evidencia. San Pablo: Coleção Liebman.

Della Vedova, Paola (2013). Il giusto processo sommario. Padova: Libreria Universitaria.

Diakonis, Antonios (2014). Grundfragen der Beweiserhebung von Amts wegen im Zivilprozess. Tübingen: Mohr Siebeck.

Doménech Pascual, Gabriel, Juan Mora-SAnguinetti (2015). "El mito de la especialización judicial”. Revista para el análisis del Derecho IndDret. $\mathrm{N}^{\circ} 1$. Barcelona.

Dond, Angelo (ed.) (2011). Elementi per una definizione di complessità processuale. Milano: Guiffrè Editore.

Dondi, Angelo, Vicenzo Ansanelli, Paolo Comoglio (2015). Processi civile in evoluzione, una prospettiva comparata. Milano: Guiffrè Editore.

European Comission Directorate General Justice (2013). Assessment of the socioeconomic impacts of the policy options for the future of the European Small Claims Regulation. Bélgica: EC.

Fairen Guillen, Víctor (1953). El juicio ordinario y los plenarios rápidos: los defectos en la recepción del derecho procesal común: sus causas y consecuencias en doctrina y legislación actuales. Barcelona: Bosch.

Falconi Puig, Juan (2015). Informe Ecuador. Inédito.

FErrari, Francesca (2012). "The Judgement on Facts in Italian Summary Proceedings", en Cornelis Hendrick van RheE, Alan Uzelac. Truth and Efficiency in Civil Litigation. Antwerp: Intersentia.

Ferres da Silva Ribeiro, Leonardo (2015). Tutela Provisoria. San Pablo: Thomson Reuter.

FERRI, Corrado (2010). "Il procedimiento sommario di cognizione". Rivista di diritto processuale. Vol. I. Padova.

Galic, Ales (2013). "A Judge's Power to disregard Late Facts and Evidence and the Goals of Civil Justice", en Vytautas Nekrosius (ed.). Recent Trends in Economy and Efficiency of Civil Procedure, Vilnius: Vilnius University.

Gajardoni, Fernando da (2008). Flexibilização procedimental: um novo enfoque para o estudo do procedimento em matéria procesual. São Paulo: Atlas.

Garderes, Santiago, Gabriel Valentin (2007). Bases para la reforma del proceso penal. Montevideo: Konrad Adenauer Stiftung, Programa Estado de Derecho para Latinoamérica.

Gascón Inchausti, Fernando, Miguel García-Casas (2015). La tutela sumaria de los derechos en el ordenamiento procesal español (Informe España). Inédito.

Giordano, Rosaria (2014). "Procedimento sommario di cognizione", in La Riforma del Processo Civile. Milano: Guiffrè Editore.

Gonçalves de Castro Mendes, Aluiso (2016). "Processos coletivos na IberoAmérica", en Instituto Iberoamericano de Derecho Procesal. Processo em Jornadas-Jornadas del Instituto Iberoamericano de Derecho Procesal, Bahia: Ius Podivm.

Guinchard, Serge et al. (2015). Droit processuel. $8^{\text {a }}$ ed. Paris: Dalloz. 
HeLlwig, Korand (1910). "Prozeßhandlung und Rechtsgeschäft", en Jenks, Stuart (coord.). Festgabe der Berliner Juristischen Fakultät für Otto von Gierke. Beslau: Marcus, vol. II.

Horvitz, María Inés, Julian López (2004). Derecho Procesal Penal Chileno. Santiago: Editorial Jurídica de Chile. Tomo II.

JAсов, Jack Sir. (1978). “Accelerating the process of law”, in Marcel Storme, Hélèn CASMAn. Towards a Justice With Human Face. Dordrecht: Springer.

Koller, Christian (2014). "Civil Justice in Austrian-German Tradition”, in Alan UzELAC (coord.). Goals of CivilJustice and Civil Procedure in Contemporary Judicial Systems. Dordrecht: Springer International Publishing.

Kramer, Xandra (2014). "The Structure of Civil Proceedings and Why It Matters: Exploratory Observations on Future ELI-UNIDROIT European Rules of Civil Procedure". Uniform Law Review. Vol. 218. Roma.

Kornhauser, Lewis (2012). "Judicial organization and administration", en Chris William SANCHIRICO (coord.). Procedural Law and Economics. Cheltenham: Edward Elgar Ed.

Landoni Sosa, Ángel, Santiago Pereira Campos (2002). "Tutela de los intereses difusos y colectivos en Uruguay”. Revista Uruguaya de Derecho Procesal. Vol. 1. Montevideo.

Langbroek, Philip, Marco Fabri (2007a). The right judge for each case. A study of case assignment and impartiality in six European judiciaries. Antwerp: Oxford.

Langbroek, Philip, Marco Fabri (2007b). "Is there a Right Judge for Each Case? A Comparative Study of Case Assignment in Six European Countries". European Journal of Legal Studies. Vol 1-2. Firenze.

Lebre de Freitas, José Miguel, Miguel Teixeira de Sousa, Rui Soares Pereira (2015). Informe Portugal. Inédito.

LegG, Micheal, Andrew Higgins (2016). "Responding to Cost and Delay Though Overriding Objectives-Successful Innovation?”, in Colon Picker, Guy SEIDMAN (coords.). The Dynamism of Civil Procedure - Global Trends and Developments. Switzerland: Springer International Publishing.

Letelier, Enrique, Pía Tavolari, Jonathan Valenzuela (2015). Informe Chile. Inédito.

LOMBARDI, Rita (2010). "Il procedimento sommario di cognizione generale", in Il Giusto processo civile. Fascicolo 2, Bologna.

Los SAntos, Mabel (2012). "El debido proceso ante los nuevos paradigmas", en La ley 2012-B. Lima.

Losardo, Martín Francisco (2015). "Creación pretoriana de las acciones de clase, la problemática...”. Lecciones y Ensayos (UBA), № 94. Buenos Aires.

Ma ko, Rafal (2014). European Small Claims Procedure: Legal Analysis of the Commission's Proposal to Remedy Weaknesses in the Current System (November 4, 2014). Brussels: European Parliamentary Research Service. 
Marcos Francisco, Diana (2016), "El nuevo juicio verbal tras la Ley 42/2015, de 5 de octubre, de reforma de la Ley 1/2000, de 7 de enero, de enjuiciamiento civil”. Revista General de Derecho Procesal. Vol. 38. Granada.

Marín GonzÁlez, Juan Carlos (2016). Tratado de las Medidas Cautelares. $2^{\text {a }}$ edición. Santiago: Editorial Jurídica de Chile.

Marin, Jeferson, Carlos Alberto Lunelli (2011). "Medio Ambiente, tutelas de urgencia y proceso colectivo”. Opinión Jurídica (U. de Medellín). Vol. 10. No 20. Medellín.

Marinoni, Luiz Gilherme (2013). "L'evoluzione della tecnica anticipatoria e della tutela preventiva in Brasile". Rivista Trimestrale di Diritto e Procedura Civile. Vol. LXVII. Milano.

Maturana, Cristián, Raúl Montero (2010). Derecho Procesal Penal. Santiago: LegalPublishing. Tomo II.

Mendoza Díaz, Juan (2015). Informe Cuba. Inédito.

Meneses Pacheco, Claudio (2017). Estudios sobre el proceso civil chileno, Valparaíso: Prolibros.

Monroy Palacios, Juan (2004). La tutela procesal de los derechos. Lima: Palestra.

Montesano, Luigi (1999). "Strumentalità e Superficialità della Cognizione Cautelare". Rivista di Diritto Processuale. Vol. Lv. Padova.

MÜlLER, Julio Guilherme (2014). "Acordo processual e gestão compartilhada do procedimento", in Alexandre Freire, Bruno Dantas, Dierle Nunes, Fredie Didier Junior, José Miguel García (coords.). Novas Tendências do processo civil: estudos sobre o projeto do novo Código de Processo Civil. Bahia: Ed. Jus Podivm. Vol. III.

OECD (2013). "Giustizia civile: come promuoverne l'efficienza?". OECD Economics Department Policy Notes, $\mathrm{N}^{\circ} 18$, Paris.

Osti, Alessandra (2016). Teoria e prassi dell'access to justice. Milano: Giuffrè Editore.

OtEIZA, Eduardo (2015). "Posibles convergencias de los procesos de reformas a la justicia civil en América Latina. Por una mayor civilidad". Revista Iberoamericana de Derecho Procesal. Vol 1. Montevideo.

Peyrano, Jorge Walter, María Carolina Eguren (2006). "Medidas autosatisfactivas y la necesidad de su regulación legal”. La Ley. Lima.

Pellegrini Grinover, Ada (2003). "Procedimientos preliminares o sumarios: alcance e importancia". Informe General (Civil Law). México: XII Congreso Mundial de Derecho Procesal.

Pereira Campos, Santiago (2016). "Uruguai", en Instituto Iberoamericano de Derecho Procesal. Processo em Jornadas- Jornadas del Instituto Iberoamericano de Derecho Procesal, Bahia: Ius Podivm.

Pérez Ragone, Álvaro (2016). "Breve aporte sobre la tutela cautelar en la nueva institucionalidad ambiental chilena", en Juan Carlos Ferrada, Francisco Pinilla, Jorge Bermúdez Soto (coords.). La Nueva Justicia Ambiental. Santiago: Thomson Reuters. 
Priori Posada, Giovanni, Christian Delgado Suárez (2016). Informe Perú. Inédito. Punzi, Carmine (2016). "Le nuove frontiere dell'arbitrato". Rivista di Diritto Processuale, Vol. LXx. $\mathrm{N}^{\mathrm{o}} 1$. Padova.

RHEE, Robert (2009). "Toward procedural optionality: private ordering of public adjudication". New York University Law Review. Vol. 84. New York.

Rivera, Rodrigo et al. (2015). Informe Venezuela. Inédito.

Seidman, Guy (2016). "The New Comparative Civil Procedure", Colin Picker, Guy SeIdman (coords.). The Dynamism of Civil Procedure - Global Trends and Developments, Dordrecht: Springer International Publishing.

Setтem, Ola Johan (2016). Applications of the "Fair Hearing" Norm in ECHR Article 6(1) to Civil Proceedings. Dordrecht: Springer International Publishing.

SorabJI, John (2013). "Prospects for Proportionality”. Civil Justice Quaterly. Vol. 32. $\mathrm{N}^{\mathrm{o}}$ 2. London.

STÜRNER, Rolf (2014). "Die Rolle des dogmatischen Denkens in Zivilprozessrecht". Zeitschrift fiur Zivilprozess. Vol. 139. Berlin.

Tamanaha, Brian (2004). On the Rule of Law. Cambridge: Cambridge University Press.

TEDoldi, Alberto (2013). Il nuovo procedimento sommario di cognizione. Torino: Zanichelli.

Trocker, Nicolo (2009). "Dal 'giusto processo' all'effetività dei remdi. L'azione' nella'elaborazione della Corte europea dei diritti dell'uomo", in Vitorio Colesanti, Claudio Consolo, Giorgio Gaja, Ferruccio Tommaseo (coords.). Il diritto processuale civile nell'avvicinamento giuridico internaazionale (omaggio ad Aldo Atardi). Padova: Editrice Università di Padova.

Tronson, Brenda. (2016). "Towards Proportionality -The 'quick, Cheap and Just' Balance in Civil Litigation”, in Colin Picker, Guy Seidman. The Dynamism of Civil Procedure - Global Trends and Developments. Dordrecht: Springer International Publishing.

UzeLAC, Alan (coord.) (2014). Goals of CivilJustice and Civil Procedure in Contemporary Judicial Systems. Dordrecht: Springer International Publishing.

Valentin, Gabriel, Hegedus, Margarita de (2015). Informe del Uruguay (Inédito)

Van RheE, Cornelis Hendrick (2004). “The Law's Delay: An Introduction”, Hendrick van RheE (ed.). The Law's Delay, Intersectie Uitgivers, Antwert: Intersentia.

Van Rhee, Cornelis Hendrick (2014). "Civil Justice in Pursuit of Efficiency", in Alan Uzelac (coord.). Goals of Civil Justice and Civil Procedure in the Contemporary World. Dordrecht: Springer International Publishing.

Verbic, Francisco, Matías Sucunza (2016). "Medidas cautelares en procesos colectivos: ausencia de régimen adecuado y modulaciones necesarias", en Augusto Morello, Gualberto Sosa, Roberto Berizonce (coord.). Códigos Procesales en lo Civily Comercial de la Provincia de Buenos Aires y la Nación. Comentados y Anotados. $4^{\text {a }}$ edición. La Plata: Platense. Tomo III.

VERDE, Giovannib (2011). "Il processo sotto l'incubo della ragionevole durata". Rivista di diritto processuale. Vol. LXVI. No 3 . Padova. 
Vitorelli, Edilson (2016). O devido processo legal coletivo, São Paulo: Revista dos Tribunais.

Villarroel Bustios, José Cesar, Jorge Omar Mostajo Barrios (2015). Informe Bolivia. Inédito

Voigt, Stefan, Nora Bialy (2013). Identifying the Determinants ofJudicial Performance. Taxpayers' Money Well Spent?. Hamburg: Institute for Research in Economic and Fiscal Issues Working Paper 201302. disponible en http://de.irefeurope. org/SITES/de.irefeurope.org/IMG/pdf/voigt_and_el-bialy_2013_final.pdf)

Watanabe, Kazuo (2004). "Cultura da sentença e cultura da pacificação", en Flavio Luiz Yarshell e Maurício Zanoide de Moraes. Estudos em homenagem à professora Ada Pellegrini Grinover. São Paulo: DPJ.

Zagrebelsky, Gustavo (1997). El derecho dúctil. Madrid: Editorial Trotta.

Zuckerman, Adrian (1994). "Quality and Economy in Civil Procedure - The Case for Commuting Correct Judgments for Timely Judgments". Oxford Journal of Legal Studies. Vol. 14. Oxford.

\section{Jurisprudencia citada}

Chile

Corte de Apelaciones de Coyhaique, 21 de enero de 2014, rol 41-2013.

Corte de Apelaciones de Punta Arenas, 27 de octubre de 2011, rol 88-2011.

Corte de Apelaciones de Punta Arenas, 4 de octubre de 2012, rol 103-2012.

Corte de Apelaciones de Punta Arenas, 7 de noviembre de 2012, rol N¹04-2012 .

Corte Suprema de Justicia de Chile, rol 5715-2012.

Corte Suprema de Chile, roles 5715-2012 y 3179-2012.

Corte de Apelaciones de San Miguel, 15 de mayo de 2014, rol 39-2014.

Corte de Apelaciones de Valparaíso, 12 de diciembre de 2001, rol No 3399-2001.

Corte Suprema, 28 de octubre de 2016, rol 111-2016.

Segundo Tribunal Ambiental de Santiago, 26 de septiembre de 2013, causa rol D-6-2013.

Tercer Tribunal Ambiental de Valdivia, rol D-15-2016.

Argentina

Corte Suprema de la Nación, 30-9-2008, "Comunidad Indígena Eben Ezer c.

Provincia de Salta. Ministerio de Empleo y la Producción”, Fallos 331:2119;

La Ley, 2008-F, p. 93.

Corte Suprema de la Nación, CSN, 8-4-08, U. 30.XLII, "Unión de Usuarios y Consumidores c. Cia. Euromédica de Salud s/Amparo".

Corte Suprema de la Nación, CSN, 25-3-03, Fallos, 326:970; La Ley, 2003-E, p. 305. 
Corte Suprema de Justicia de la Nación, "Barrick Exploraciones Argentinas S.A. y otro c/ Estado Nacional s/ acción declarativa de inconstitucionalidad" - B. 140 XLVII - res. del 3 de julio de 2012.

Corte Suprema de Justicia de la Nación, "Asociación de Esclerosis Múltiple de Salta c/ Ministerio de Salud - Estado Nacional s/ acción de amparo - medida cautelar", res. del 18 de diciembre de 2003 - Fallos: 326:4931.

Corte Suprema de Justicia de la Nación, Halabi, Ernesto c/ PEN - Ley 25.873, Dto. 1563/04 s/ amparo ley 16.986 (24/02/2009), Fallos 332:111.

Corte Suprema de Justicia de la Nación, "Neira, Luis Manuel y otra c/ Swiss Medical Group S.A.”, Fallos: 326:2906, sentencia del 21 de agosto de 2003.

Corte Suprema de Justicia de la Nación, "Pesquera Leal S.A. c/ Estado Nacional - Secretaría de Agricultura, Ganadería y Pesca s/ medida cautelar", sentencia del 19 de octubre de 2000 .

\section{Colombia}

Corte Constitucional Colombiana Sentencia C-284/14 CC.

Corte Constitucional Colombiana en 2004 (Sentencia T-25).

Brasil

Supremo Tribunal Federal (Brasil) 2009 en decisión STA-AgR n. 175.

Ecuador

182 Corte Constitucional sobre medidas cautelares Corte Constitucional del Ecuador. Sentencia $N^{\circ} 0034-2013$.

Bolivia

Sentencia Constitucional 1889/2011-R Sucre, 7 de noviembre de 2011 (201123059-47-AL).

Perú

Tribunal Constitucional del Perú. 2437-13-AA.

Tribunal Constitucional del Perú. Expte. N. 0025-2005-PI/TC y 0026-2005-PI/ TC. 25 de abril de 2006. párr. 26.

Tribunal Constitucional del Perú. Expte. N. ${ }^{\circ}$ 2945-2003-AA/TC. 20 de abril de 2004. parr. 30. 